\title{
Additively Manufactured Intensified Device for Enhanced Carbon Capture
}

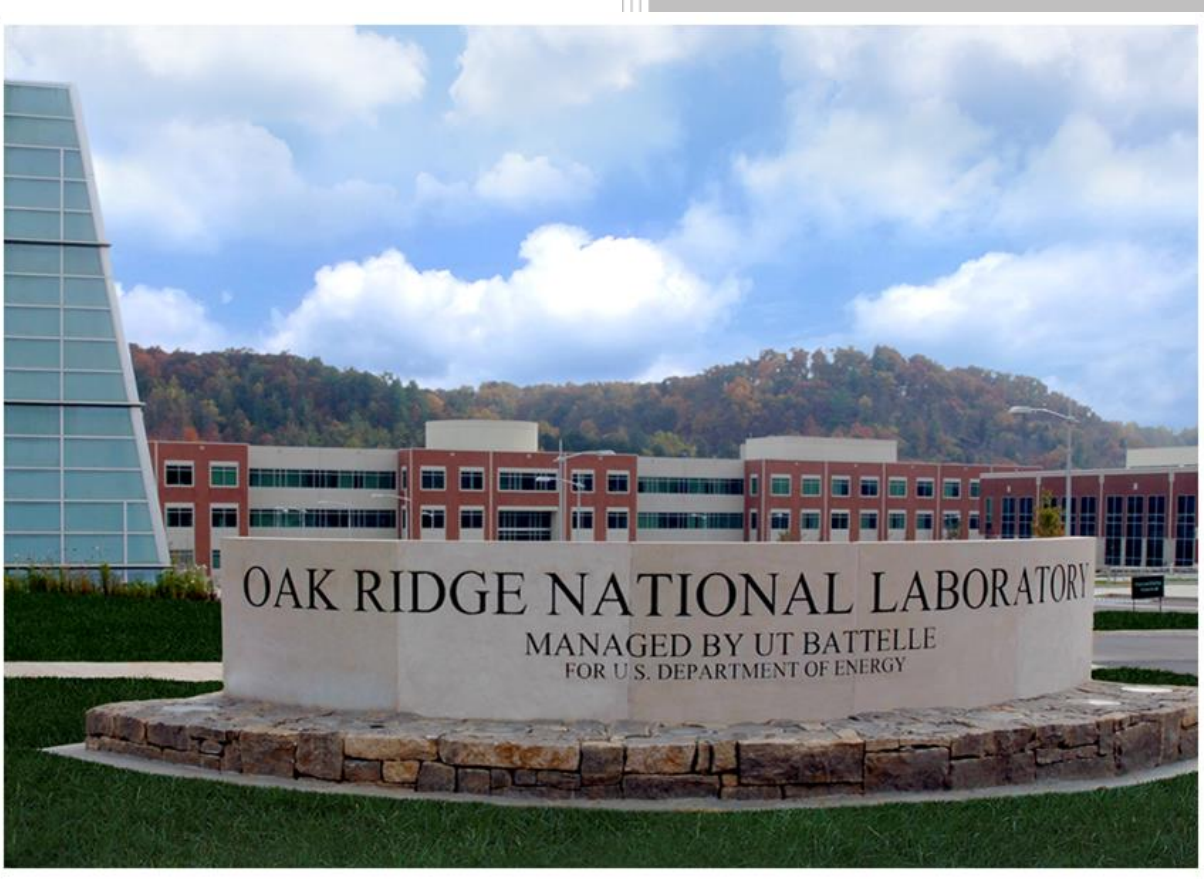

\section{Approved for public release.} Distribution is unlimited.
Costa Tsouris

Eduardo Miramontes

Canhai Lai

Lonnie Love

Xin Sun

December 30, 2019 


\title{
DOCUMENT AVAILABILITY
}

Reports produced after January 1, 1996, are generally available free via US Department of Energy (DOE) SciTech Connect.

Website www.osti.gov

Reports produced before January 1, 1996, may be purchased by members of the public from the following source:

\author{
National Technical Information Service \\ 5285 Port Royal Road \\ Springfield, VA 22161 \\ Telephone 703-605-6000 (1-800-553-6847) \\ TDD 703-487-4639 \\ Fax 703-605-6900 \\ E-mailinfo@ntis.gov \\ Website http://classic.ntis.gov/
}

Reports are available to DOE employees, DOE contractors, Energy Technology Data Exchange representatives, and International Nuclear Information System representatives from the following source:

Office of Scientific and Technical Information

PO Box 62

Oak Ridge, TN 37831

Telephone 865-576-8401

Fax 865-576-5728

E-mail reports@osti.gov

Website https://www.osti.gov/

This report was prepared as an account of work sponsored by an agency of the United States Government. Neither the United States Government nor any agency thereof, nor any of their employees, makes any warranty, express or implied, or assumes any legal liability or responsibility for the accuracy, completeness, or usefulness of any information, apparatus, product, or process disclosed, or represents that its use would not infringe privately owned rights. Reference herein to any specific commercial product, process, or service by trade name, trademark, manufacturer, or otherwise, does not necessarily constitute or imply its endorsement, recommendation, or favoring by the United States Government or any agency thereof. The views and opinions of authors expressed herein do not necessarily state or reflect those of the United States Government or any agency thereof. 
ORNL/SPR-2019/1423

Energy and Transportation Science Division

FWP-FEAA130

Additively Manufactured Intensified Device for Enhanced Carbon Capture

\author{
SUBMITTED BY \\ Costas Tsouris, Eduardo Miramontes, Canhai Lai, Lonnie Love, Xin Sun \\ Oak Ridge National Laboratory \\ 1 Bethel Valley Road \\ Oak Ridge, TN 37930
}

\title{
PRINCIPAL INVESTIGATOR
}

\author{
Xin Sun, Ph.D. \\ 8655763711 \\ sunx1@ornl.gov
}

\author{
Prepared by \\ OAK RIDGE NATIONAL LABORATORY \\ Oak Ridge, TN 37831-6283 \\ managed by \\ UT-BATTELLE, LLC \\ for the \\ US DEPARTMENT OF ENERGY \\ under contract DE-AC05-00OR22725
}

December 30, 2019 



\section{CONTENTS}

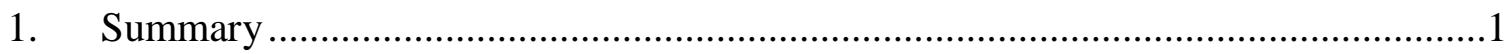

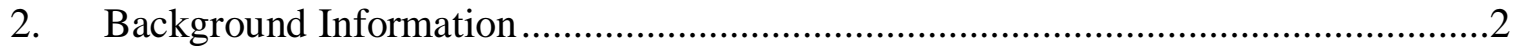

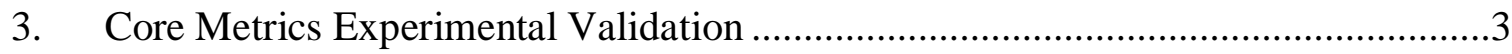

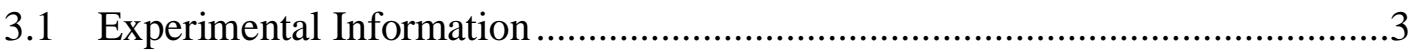

3.1.1 Commercial and Additively Manufactured Packing Elements .................3

3.1.2 Intensified Device ....................................................................

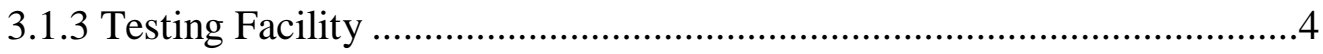

3.1.4 Experimental Methods .................................................................6

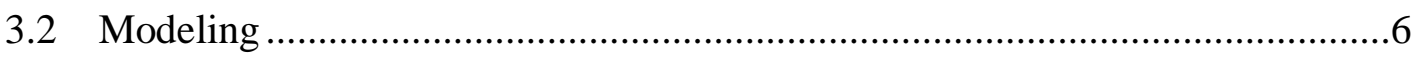

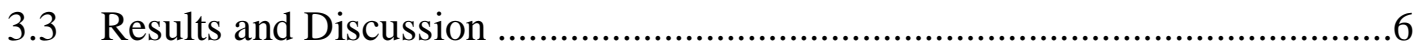

3.3.1 Intensified Device Revision ......................................................6

3.3.2 Pressure Drop for Dry System ..................................................

3.3.3 Pressure Drop for Irrigated System..............................................

3.3.4 Wettability of Packing Elements .....................................................11

3.3.5 Discussion .............................................................................. 12

4. Device Scale Validation Through Design of Experiments ..................................13

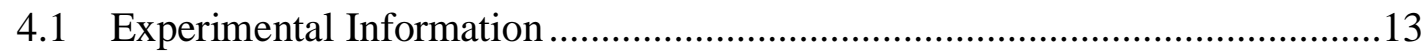

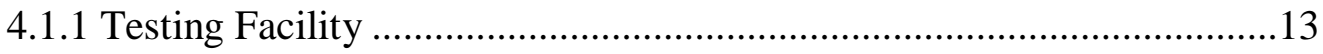

4.1.2 Experimental Methods ............................................................ 15

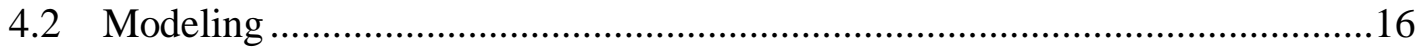

4.2.1 Heat and Mass Transfer Modelling ...................................................16

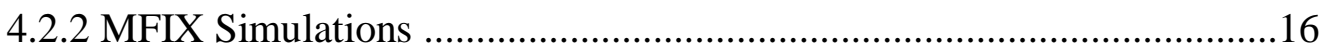

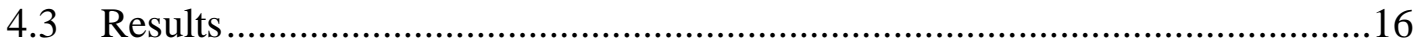


4.3.1 Non-Reactive Heat Transfer ...........................................................16

4.3.2 Reactive System Mass Transfer ..........................................................19

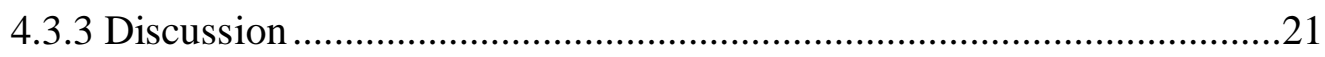

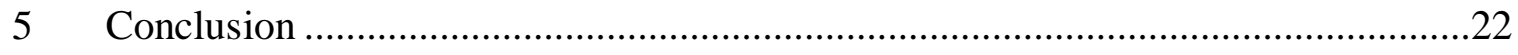




\section{Figures}

Figure 1. Commercial and 3D printed packing devices used in pressure-drop and wettability measurements.

Figure 2. Printed 8-inch packing elements used for pressure-drop and wettability measurements

Figure 3. Design of aluminum intensified packing device.

Figure 4. First generation aluminum intensified device. .4

Figure 5. Experimental system used for experimental validation of device core metrics. 5

Figure 6. Leak testing of first generation aluminum intensified device. 7

Figure 7. 100- $\mu \mathrm{m}$ gap found in the design file of the intensified device.........................

Figure 8. Second generation intensified device. .........................................................

Figure 9. Dry pressure drop and model predictions for 8 -inch column.........................8

Figure 10. Dry pressure drop and model predictions for 16 -inch columns. .......................

Figure 11. Dry pressure drop comparison between printed polymer packing elements and printed aluminum intensified device.

Figure 12. Pressure drop measurements and model predictions for irrigated 8 -inch column.

Figure 13. Comparison of pressure drop between aluminum intensified device and polymer prints in irrigated 8-inch column.

Figure 14. Pressure drop measurements for aluminum intensified device in an irrigated 8-inch column.

Figure 15. Wettability measurements in terms of mass of water retained per unit surface area of packing elements for 3D printed polymer packing.

Figure 16. Wettability measurements in terms of mass of water retained per unit surface area of packing elements for commercial, polymer, and metal intensified packing.

Figure 17. Schematic of testing facility for the non-reactive experiments.

Left: Experimental apparatus; Right: Absorption column.

Figure 18. Liquid distribution system for absorption column

Figure 19. Schematic of testing facility and absorption column.

CPE: Commercial Packing Element. C: $\mathrm{CO}_{2}$ measurement.

Figure 20. Liquid temperature profile along absorber height for non-reactive experiments. All variables were kept constant except the liquid flow rate 
Figure 21. Parity plot for Uncooled Air- $\mathrm{H}_{2} \mathrm{O}$ system. Experimental vs simulated

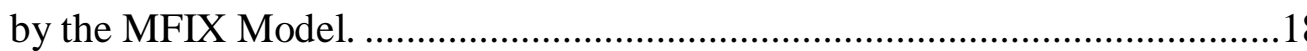

Figure 22. Parity plot for Cooled Air- $\mathrm{H}_{2} \mathrm{O}$ system. Experimental vs simulated by the MFIX Model.

Figure 23. Top: Effect of cooling on $\mathrm{CO}_{2}$ concentration and molar $\mathrm{CO}_{2}$ capture rate at $360 \mathrm{LPM}$ of air and $90 \mathrm{LPM}$ of $\mathrm{CO}_{2}$. Middle: Time-dependent temperature profiles. Bottom: Steady-state liquid temperature profile before and after cooling 


\section{Tables}

Table 1. Calculated heat transfer coefficients for each experimental case .....................18

Table 2. Improvements in capture efficiency for constant $\mathrm{CO}_{2}$ and constant air flow .....21

Table 3. Experimental Cases in Unreactive Irrigated Absorption Column Experiments .25

Table 4. Heat losses due to vaporization and through the walls ...................................26 


\section{SUMMARY}

Additively manufactured packed bed devices for the enhancement of carbon capture were successfully developed, built, characterized, and tested in this project. The objective was to demonstrate that in situ cooling of chemical absorption could have beneficial effects on the absorption rate of $\mathrm{CO}_{2}$. This was achieved in two stages, divided between FY 2018 and FY 2019. First, the feasibility of printing conventional packing elements was investigated, and the core hydrodynamic metrics were experimentally validated. The data obtained in those studies informed the operating conditions set for the next stage, which was to validate the efficacy of in situ cooling provided by an additively manufactured packed bed element, referred to as the intensified device. The intensified device is designed to enable heat exchange between an internally flowing coolant and the gas-liquid system flowing on the external corrugated surface of the packing. Polymer and metal were both considered as the base materials for the device, and comparative studies on hydrodynamic properties were performed. These considerations, as well as thermal properties and leak tests led to aluminum being chosen as the base material for experimental validation of capture enhancement. The experimental validation was first conducted under non-reactive conditions, and after establishing heat-exchange capabilities, was subsequently conducted under reactive conditions. These studies demonstrated that in situ cooling can benefit absorption given the appropriate operating conditions.

The feasibility of 3D printing packed bed elements was demonstrated by adopting the packing geometry of commercially available structured packing elements and reproducing them using 3D printing. Polymer and aluminum based packing elements were additively manufactured, including 8- and 16-inch diameter polymer based packing elements, as well as an aluminum based intensified device. Two 16-inch diameter commercially available packing elements from Sulzer, one made of stainless steel and another made of plastic, were obtained for a comparative hydrodynamic study. Measurements were performed using two columns, 8- and 16-inch diameter, that were especially set up for hydrodynamic testing at the National Transportation Research Center of the Oak Ridge National Laboratory.

Hydrodynamic studies of additively manufactured packed beds showed that metal based packing elements are much better wetted by aqueous solution than plastic elements. Values of water retained per unit surface area by stainless-steel and aluminum packing elements are very similar and much greater than water retained per unit surface area of plastic packing elements. Based on these results, it was expected that $\mathrm{CO}_{2}$ capture efficiency would be higher for a packed column with metal structured packing than that for the same column with plastic packing. The pressure drop for dry and irrigated column for a varying packing element diameter was also measured, and results were compared with theoretical values obtained from an existing hydrodynamic model. The pressure drop across an intensified packing device was measured with and without liquid flow, and results showed similar behavior. Only at high gas flow velocities, the pressure drop increased due to the presence of liquid. 
The heat and mass transfer behavior of an absorption column employing the intensified device was subsequently studied using a pilot-scale experimental column set up, as described in this report. The objective of this phase was to simply demonstrate that cooling the absorption column in situ could enhance the capture of $\mathrm{CO}_{2}$ by MEA, under some set of operating conditions, and to further characterize the relationship between absorption enhancement and operating conditions. This phase of the project was conducted in two stages. First, heat transport was studied in a non-reactive system, containing only air and water in lieu of flue gas and amine solvent. Having established the heat exchange capabilities of the device, heat and mass transport were subsequently studied with a reactive system where $\mathrm{CO}_{2}$ and MEA were introduced.

The pressure drop of the aluminum intensified device was found to compare favorably to stainless steel commercial packing elements, but was significantly higher than that of the polymer prints. Results from carbon capture studies demonstrated the heat exchange capabilities of the intensified device, and more importantly that in situ heat exchange does indeed enhance carbon capture. The heat-exchange capabilities of the device were established in the non-reactive stage of the carbon capture studies, where internal cooling was shown to drastically reduce the temperature of the hot gas-liquid system. The heat-transfer behavior was confounded by the vaporization of water which removed heat from the system and substantially reduced the temperature, even prior to the activation of cooling. Despite this behavior, substantial reduction of the temperature was achieved compared to the steady-state behavior of the system before cooling. The heat transfer coefficient of the intensified device was estimated using temperature measurements obtained in this study. In experiments with the reactive system, temperature measurements were again collected, concurrently with mass transfer measurements. Inlet and outlet concentrations of $\mathrm{CO}_{2}$ were measured, and the $\mathrm{CO}_{2}$ capture rate was calculated based on a mass balance of the absorption column. These measurements showed unequivocally that in situ cooling can enhance $\mathrm{CO}_{2}$ capture under certain conditions. The magnitude of the improvement was found to depend strongly on the flow rates of air and $\mathrm{CO}_{2}$, and on the concentration of $\mathrm{CO}_{2}$.

\section{BACKGROUND INFORMATION}

Conventional equipment designs for carbon capture by solvent absorption are currently based on gas-liquid absorption columns for mass transfer followed by desorption columns for solvent regeneration and recycling. $\mathrm{CO}_{2}$ absorption is a complex process because thermodynamically it is favored by lower temperatures, but kinetically it is faster at higher temperatures. Thus, there should be an optimal set of operating parameters, including flowrates and inlet gas and liquid temperatures, that would maximize the $\mathrm{CO}_{2}$ capture efficiency. Complicating further the phenomenon, the reaction of $\mathrm{CO}_{2}$ with amines dissolved in the solvent is exothermic, thus increasing the temperature of the system. Although the temperature increase is dampened by water vaporization into the gas phase, absorption of $\mathrm{CO}_{2}$ by amines leads to a gradual increase in the solvent temperature as it trickles down the packed column. A temperature increase reduces the solvent's $\mathrm{CO}_{2}$ capacity, bringing about the need to cool the solvent along the column. Cooling can be done ex situ by a conventional heat exchanger or in situ by an intensified packing element that 
allows heat exchange between an internally flowing cooling fluid and the gas-liquid system flowing on the external surface of the corrugated sheets. In this study, an intensified packing element has been additively manufactured for the purpose of in situ cooling of the solvent. This report describes the efforts undertaken to develop and test such a device.

\section{CORE METRICS EXPERIMENTAL VALIDATION}

\subsection{EXPERIMENTAL INFORMATION}

\subsubsection{Commercial and Additively Manufactured Packing Elements}

Commercial and 3D printed 8- and 16-inch diameter devices used in this study are shown in Figure 1. Mellapak $250 \mathrm{Y}$ was chosen as the packing geometry for the project. Packing elements that deviate from the nominal packing density were also manufactured, as shown in Figure 2.
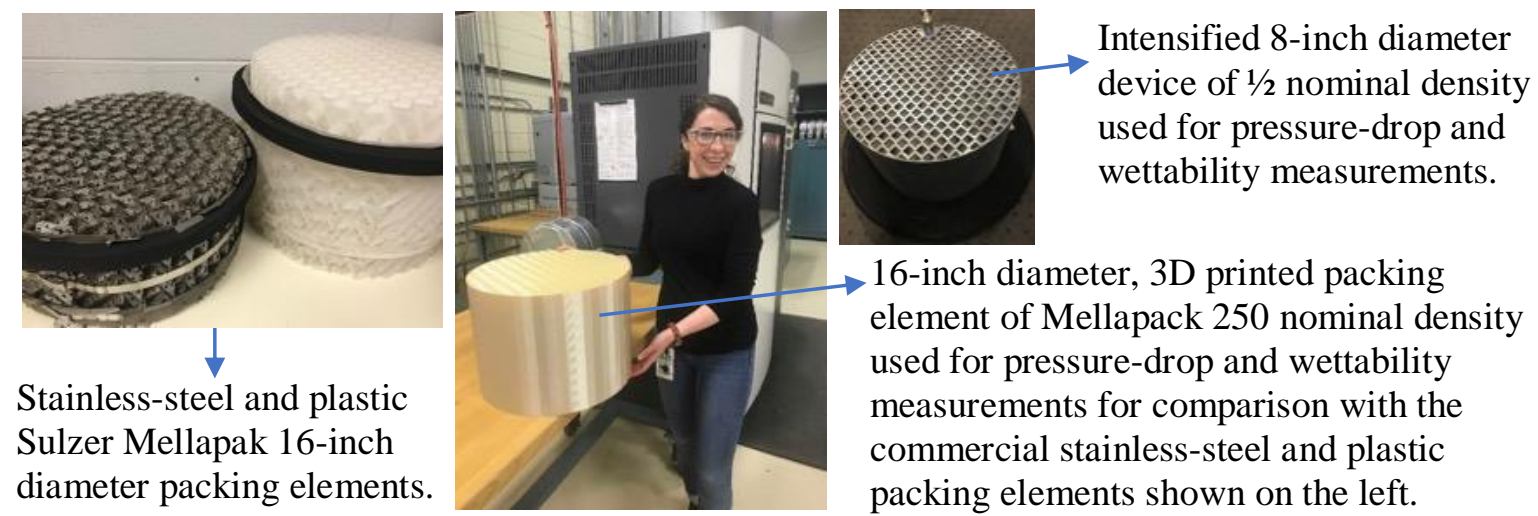

Figure 1. Commercial and 3D printed packing devices used in pressure-drop and wettability measurements.

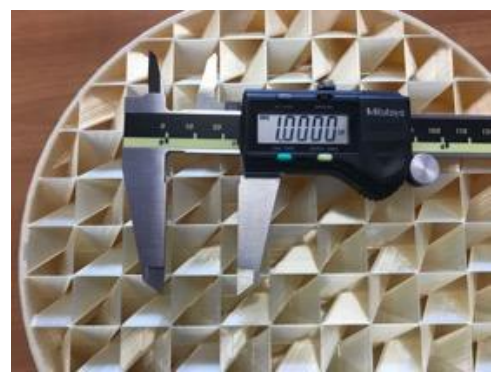

Nominal

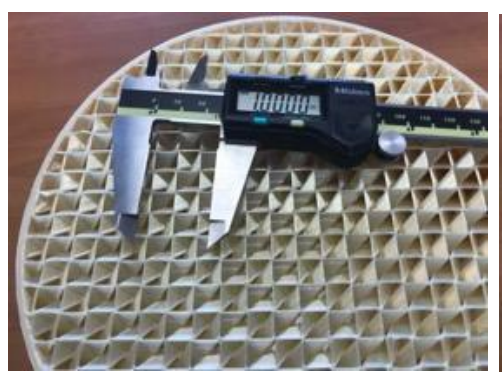

$1 / 2$ Nominal

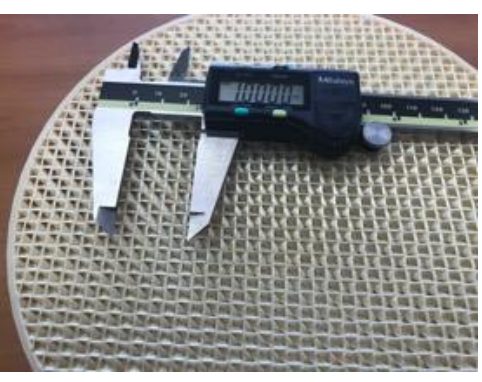

1/4 Nominal

Figure 2. Printed 8-inch packing elements used for pressure-drop and wettability measurements.

\subsubsection{Intensified Device}

Providing in situ cooling to the absorber requires the incorporation of a third fluid into the packing element. The solution developed in this project is a packing device with double walled corrugated sheets that allows fluid to flow in the space between the baffles, as shown in Figure 3A. The device uses a $25.4 \mathrm{~mm}$ cellular structure, shown as $1 / 2$ nominal in Figure 2, and incorporates a manifold 
that allows fluid to enter through the bottom left side of the packing and flow through the baffles from up and to the right (see Figures 3A).

The intensified device was manufactured using aluminum because of its high thermal conductivity. (Figures 3 B-D). The print was made using a laser powder bed system (Concept Laser XLine). Figure $3 \mathrm{E}$ shows one of the first layers of the printed design. The finished aluminum print is shown in Figure 4.

A. Cut away of packing showing fluid channels inside the baffle walls

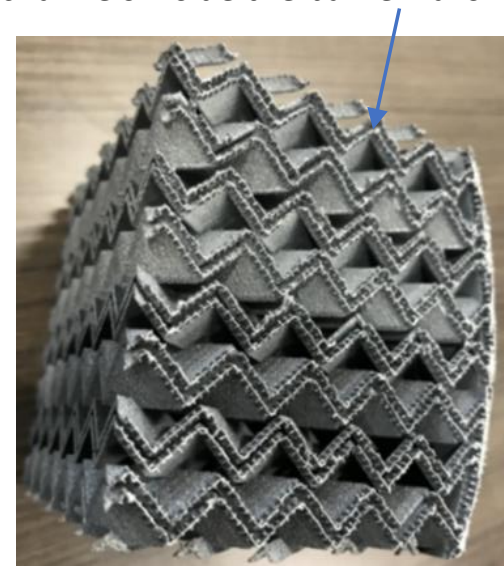

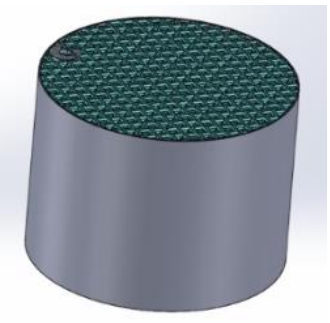

B. Packing model

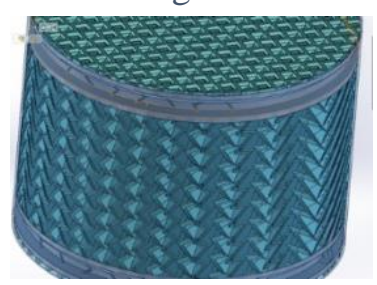

D. Fluid passages within baffles

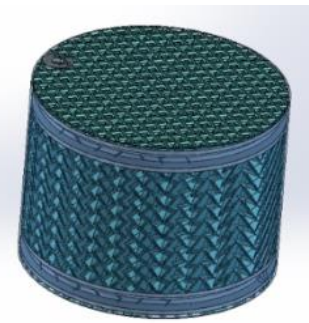

C. Packing manifold

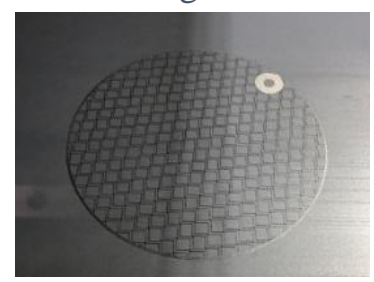

E. Early layer of aluminum print

Figure 3. Design of aluminum intensified packing device.

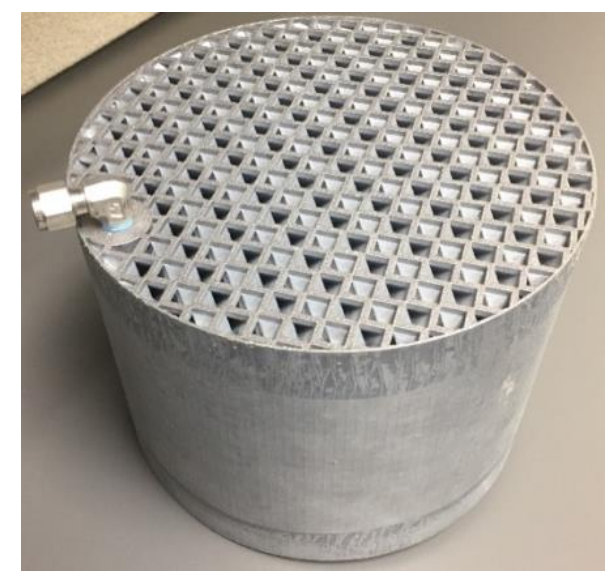

Figure 4. First generation aluminum intensified device.

\subsubsection{Testing Facility}

A testing facility was set up to allow measurements with 16- and 8-inch diameter packing materials. Initially, a 16-inch diameter column was set up for comparative studies between baseline commercial and 3D Printed Mellapak packing elements. Due to the extended period of time that was needed to prepare 3-D printed packing prototypes, it was decided to switch from 16- to 8-inch 
diameter with the objective of reducing the printing time and performing further measurements with 3-D printed materials in a timely manner. The extended setup consisting of two columns of 16- and 8-inch diameters is shown in Figure 5A. A new blower was added to the system to allow higher gas flowrates that were necessary for the experiments.

In Figure 5B, it is shown how packing elements were introduced in the 8-inch diameter column for simultaneous temperature and pressure measurements at different points as indicated on the graph. A data acquisition system was developed to allow such measurements. Furthermore, an irrigation system has been constructed and placed on top of the packing elements for solvent distribution as shown in Figure 5C.

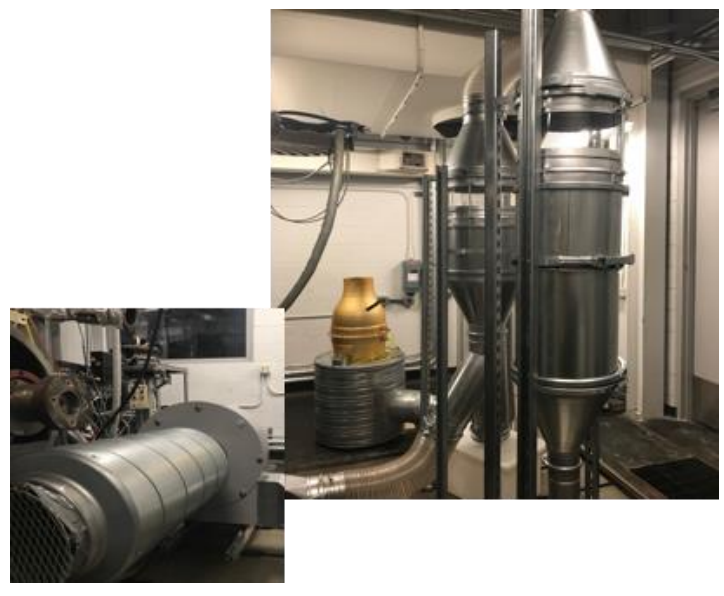

Figure 5A. Testing facility.

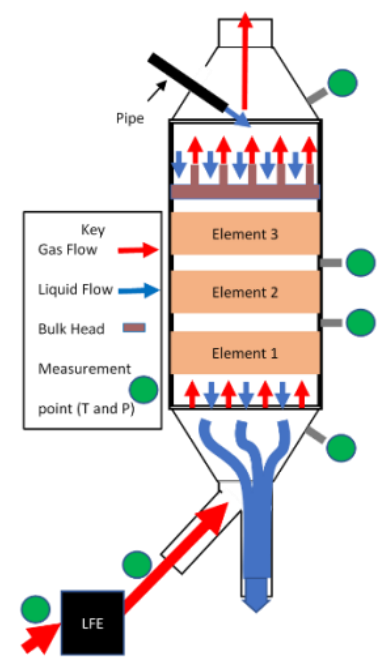

Figure 5B. Column internal parts and measurement points.

Top of solvent distributor

Top of 3D printed column packing

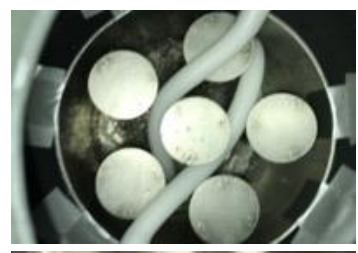

Bottom of solvent distributor

On the right, Stephen Bolton, a Chemical Engineering student from the University of Delaware, performs pressure drop measurements.

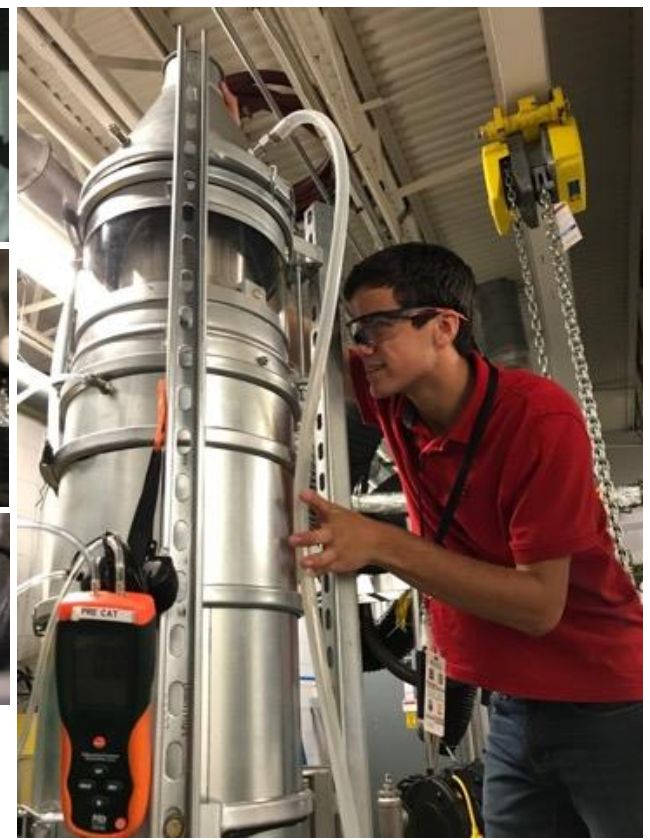

Figure 5C. Experimental system used for experimental validation of device core metrics. 


\subsubsection{Experimental Methods}

Pressure Drop: A hand held device, shown mounted on the column in Figure 5, has been used for pressure drop measurements between two points along the column (see Figure 4B) as a function of gas velocity for the dry system and gas and liquid velocities for the irrigated system.

Wettability: Basic wettability measurements for commercial Mellapak 250 baseline 16-inch diameter packing elements, including Sulzer stainless-steel and plastic elements, as well as for a 16-inch 3D printed nominal-density element as shown in Figure 1, were obtained for comparison. Sample treatment included submersion in water, removal from water, and weight gain measurements after the following actions: (1) mild shaking, (2) further shaking, (3) more shaking and drying of the external surface, (4) additional shaking and drying of the external surface. These sample treatments were consistent for all packing elements, and the weight gain measurements were divided by the surface area of each sample for comparison.

Liquid Holdup: The liquid holdup was measured by placing the water feed tank on a scale and measuring the weight of water retained in the column. Water was fed to the column from the top and recycled back to the feeding tank from the bottom of the column. The mass of water retained by the column was measured first without the packing elements, and then, with three 8 -inch diameter packing elements of $1 / 2$ nominal density (see Figure 2). The difference between these two values is the mass of water retained by the packing elements. The liquid holdup is the volume of water retained by the packing elements over their total free volume. Three packing elements were used to minimize the experimental error.

\subsection{MODELING}

Hydrodynamic modeling of dry and irrigated packed columns is discussed in the Appendix of this document.

\subsection{RESULTS AND DISCUSSION}

\subsubsection{Intensified Device Design Revision}

Leak testing of the aluminum intensified device revealed a leak emanating from the internal coolant channels. As shown in Figure 6, leak testing fluid flowing inside the corrugated sheets formed bubbles on the external surface of the channels. After detailed inspection of the design, a flaw in the design was detected: a 100- $\mu \mathrm{m}$ gap situated between the packing and outer sleeve, shown in Figure 7. Remarkably, the 3D printer had a resolution sufficiently high to faithfully reproduce this gap which had mistakenly been included in the design. 


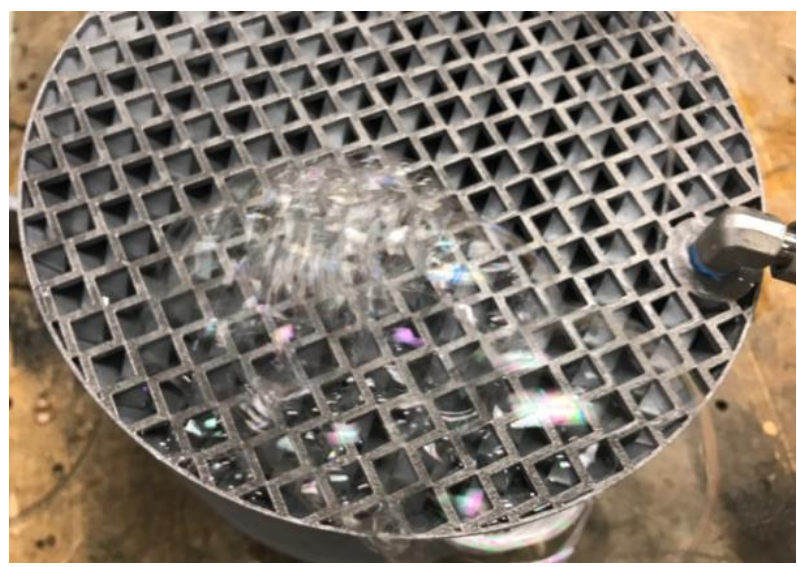

Figure 6. Leak testing of first generation aluminum intensified device.
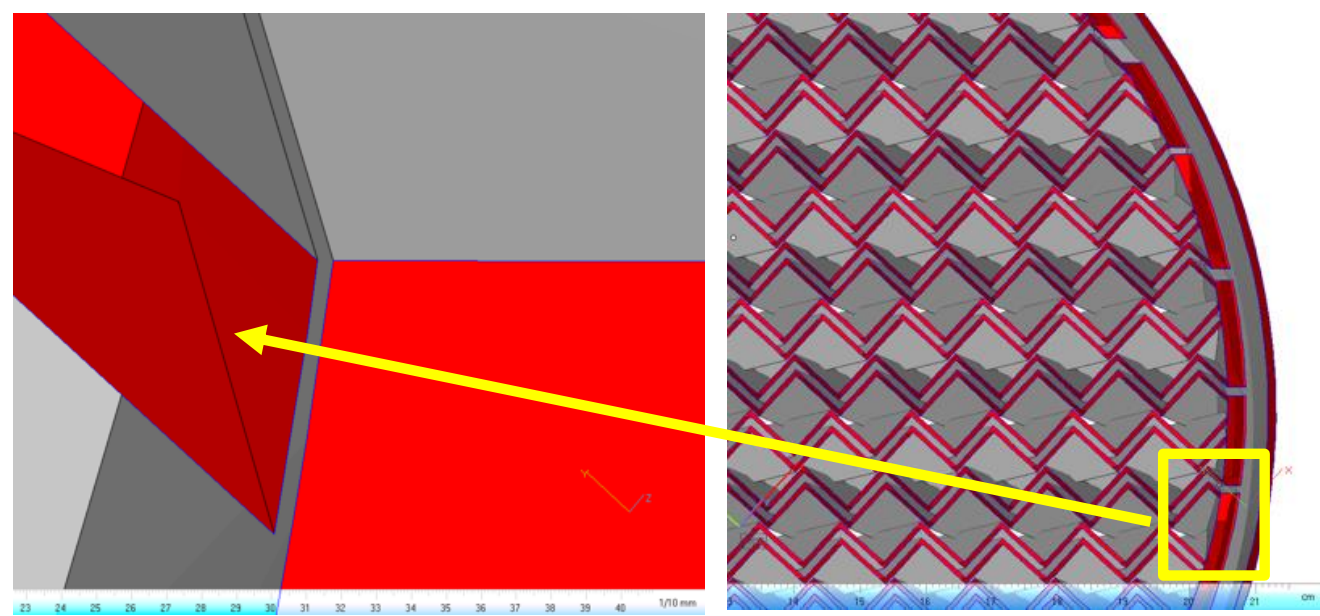

Figure 7. 100- $\mu \mathrm{m}$ gap found in the design file of the intensified device.

After the discovery of the 100- $\mu \mathrm{m}$ gap, the design was corrected, and some other alterations were made during the process. The inlet and outlet fittings were moved from top and bottom to the sides, which allows the device to sit flush on other packing elements. An outer sleeve was added for structural support and to facilitate mounting. The second generation intensified device resulting from this redesign is shown in Figure 8. This intensified device was also tested for leaks and none were detected, which allowed for it to be used for pressure drop measurements and subsequent heat and mass transfer testing.
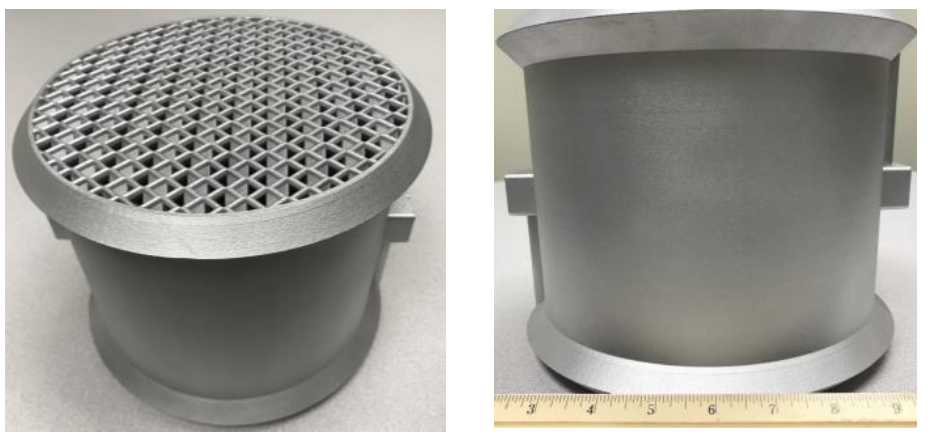

Figure 8. Second generation intensified device. 


\subsubsection{Pressure Drop for Dry System}

Dry pressure-drop experiments were performed with both 8- and 16-inch columns. First, for the 8inch diameter column, a Leeson motor controller was used to vary the gas flow into the column. For each of ten different gas velocities and for each of the three 8-inch packing elements of Figure 2 , the pressure drop across the packing element was measured. The results are shown in Figure 9 for gas flowrates ranging from $55-153 \mathrm{~L} / \mathrm{min}$. Element \#1 is the nominal density packing element shown in Figure 2, Element \#2 is the $1 / 2$ nominal density, and Element \#3 is the 1/4 nominal density. Results in Figure 9 show that the pressure drop increases with increasing packing density, which was expected. A relatively low pressure drop was measured for all elements. The error between experimental data and model predictions for this column is $13.4 \%$ for the nominal element, $9.3 \%$ for the $1 / 2$ nominal, and $29.4 \%$ for the $1 / 4$ nominal.

Dry pressure drop measurements and model predictions were also performed for the 16-inch diameter column. For this column, only one gas flow rate was used. This flow rate ( $1500 \mathrm{ft} 3 / \mathrm{min})$ is the maximum output of the blower used for the larger column. The experimental and theoretical dry pressure drops for each of the three 16-inch packing elements are shown in Figure 10.

Dry pressure drop measurements were subsequently performed on the second generation aluminum intensified device for an 8 -inch column. The results were compared to those of the $1 / 2$ nominal density printed polymer packing element, as shown in Figure 11. The aluminum intensified device was found to have significantly higher pressure drop than the polymer, especially at higher gas flow rates.

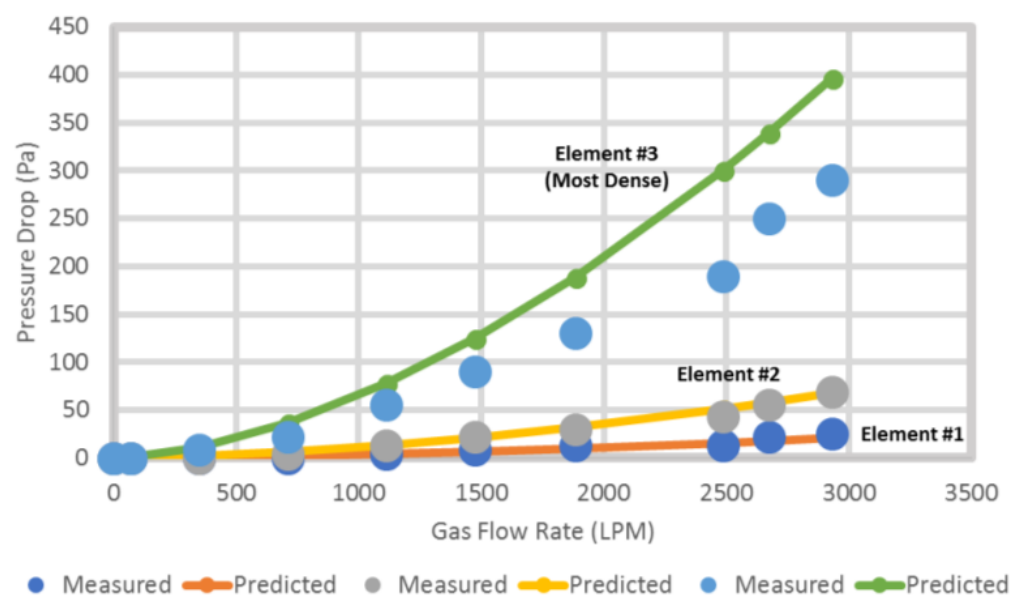

Figure 9. Dry pressure drop and model predictions for 8-inch column. 


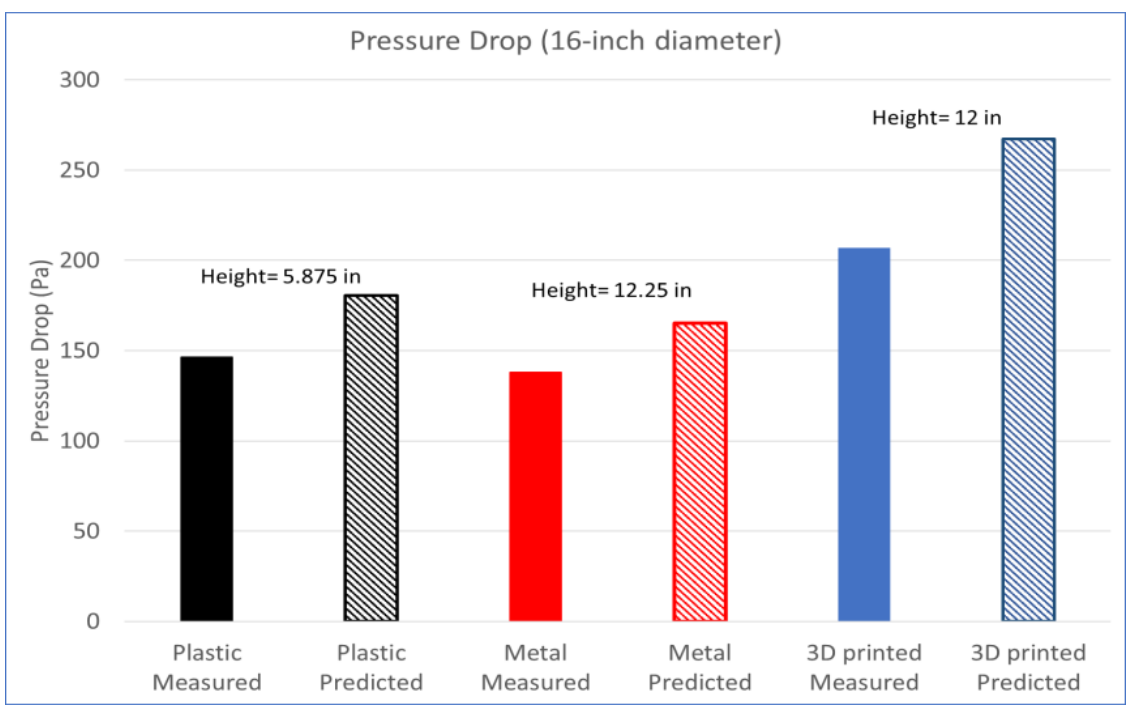

Figure 10. Dry pressure drop and model predictions for 16-inch columns.

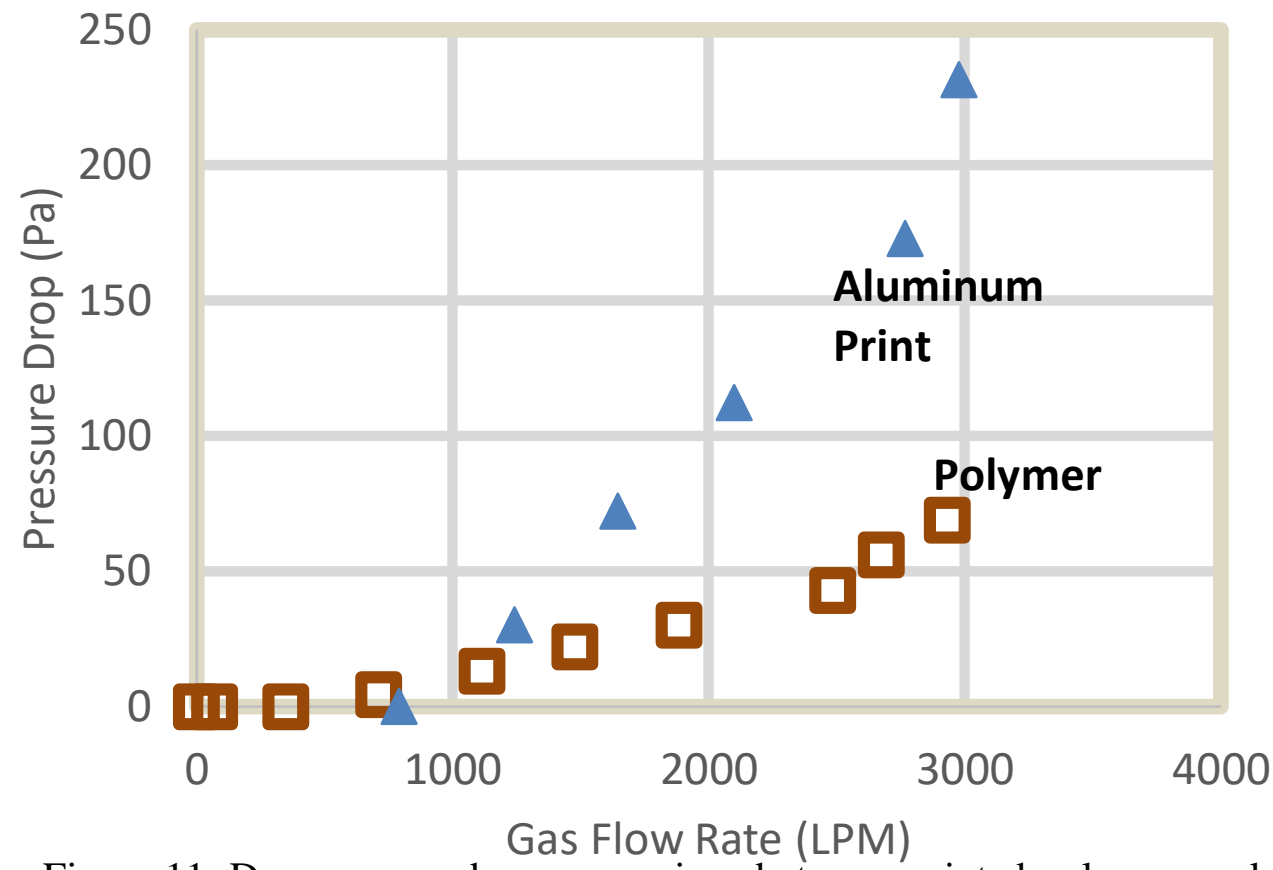

Figure 11. Dry pressure drop comparison between printed polymer packing elements and printed aluminum intensified device.

\subsubsection{Pressure Drop for Irrigated System}

Pressure drop measurements with the irrigated packed column were also performed. The experimental system shown in Figure 5 was used for these measurements. Pressure drop data obtained with the 3D printed 8-inch diameter devices are shown in Figure 12. These data show that the pressure drop increased as the liquid flowrate increased, as predicted by the model, although to a much lesser degree than predicted.

A comparison between printed polymer and the printed aluminum intensified device was also 
conducted for the 8-inch irrigated column, which is shown in Figure 13. The pattern observed in the dry column holds, and the aluminum intensified device exhibits a significantly higher pressure drop than the polymer prints, even at low flow rates, but to a higher degree in high flow rates. The complete set of irrigated column pressure measurements for water flow rates between 0 and 3.75 LPM is shown in Figure 14. These measurements show pressure drop rising with water and air flow rates, as predicted by packed column models. The final data point for 3.75 LPM did not rise as expected due to a suspected air leak in the column at that flowrate.

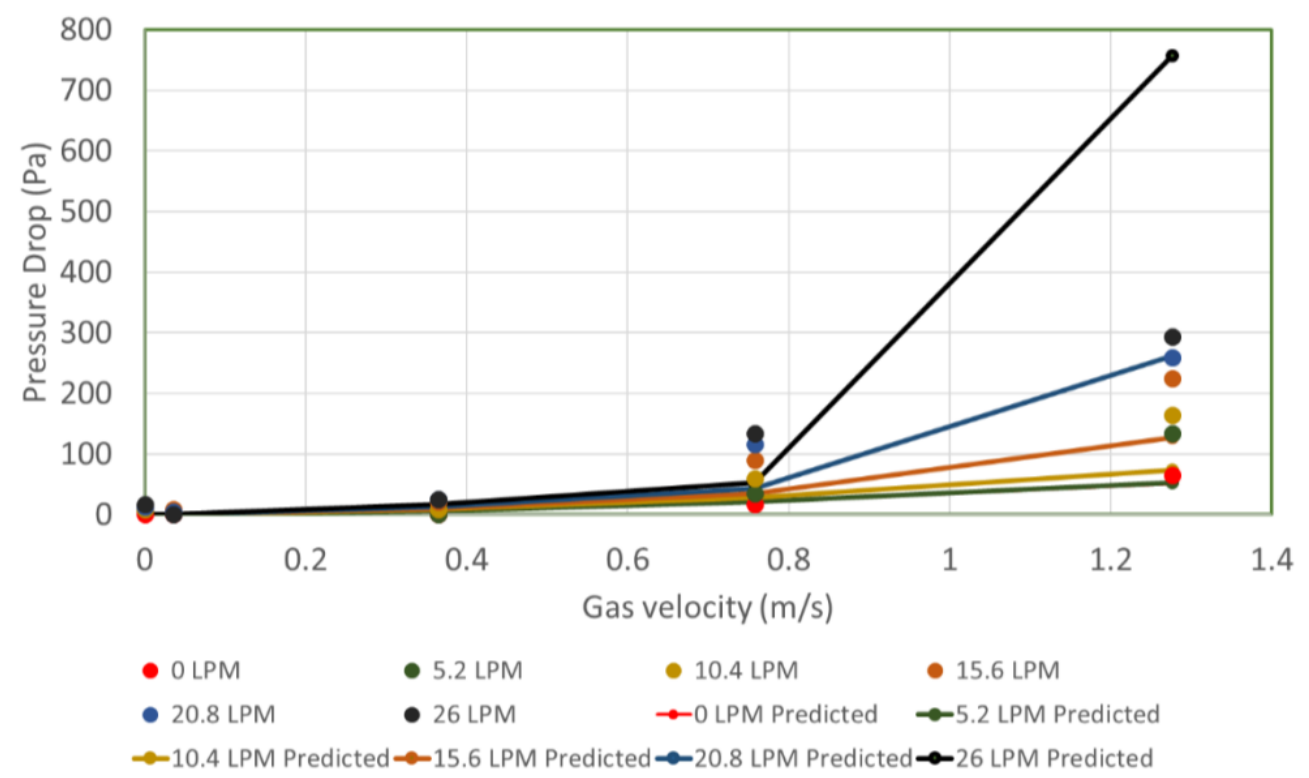

Figure 12. Pressure drop measurements and model predictions for irrigated 8 inch column.

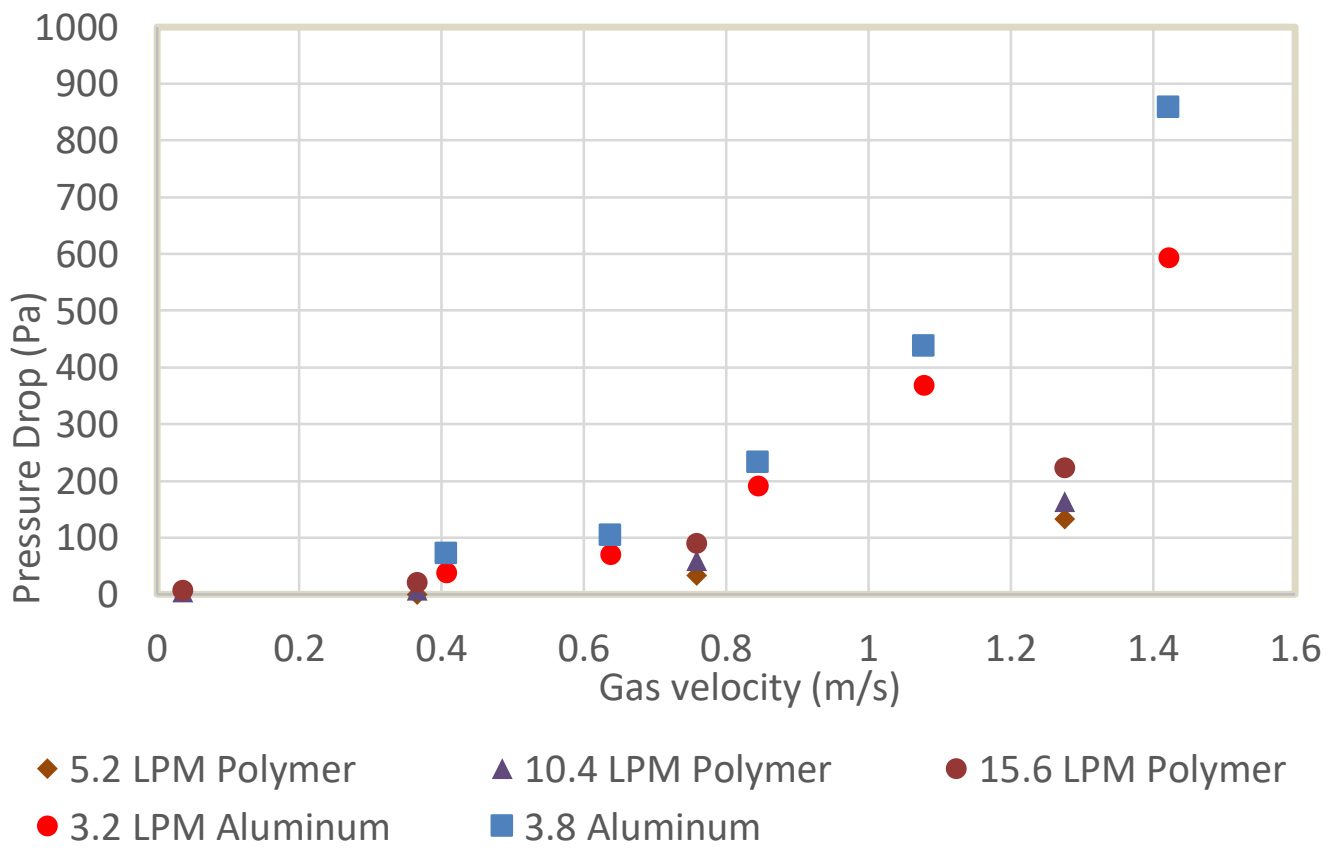

Figure 13. Comparison of pressure drop between aluminum intensified device and polymer prints in irrigated 8-inch column. 


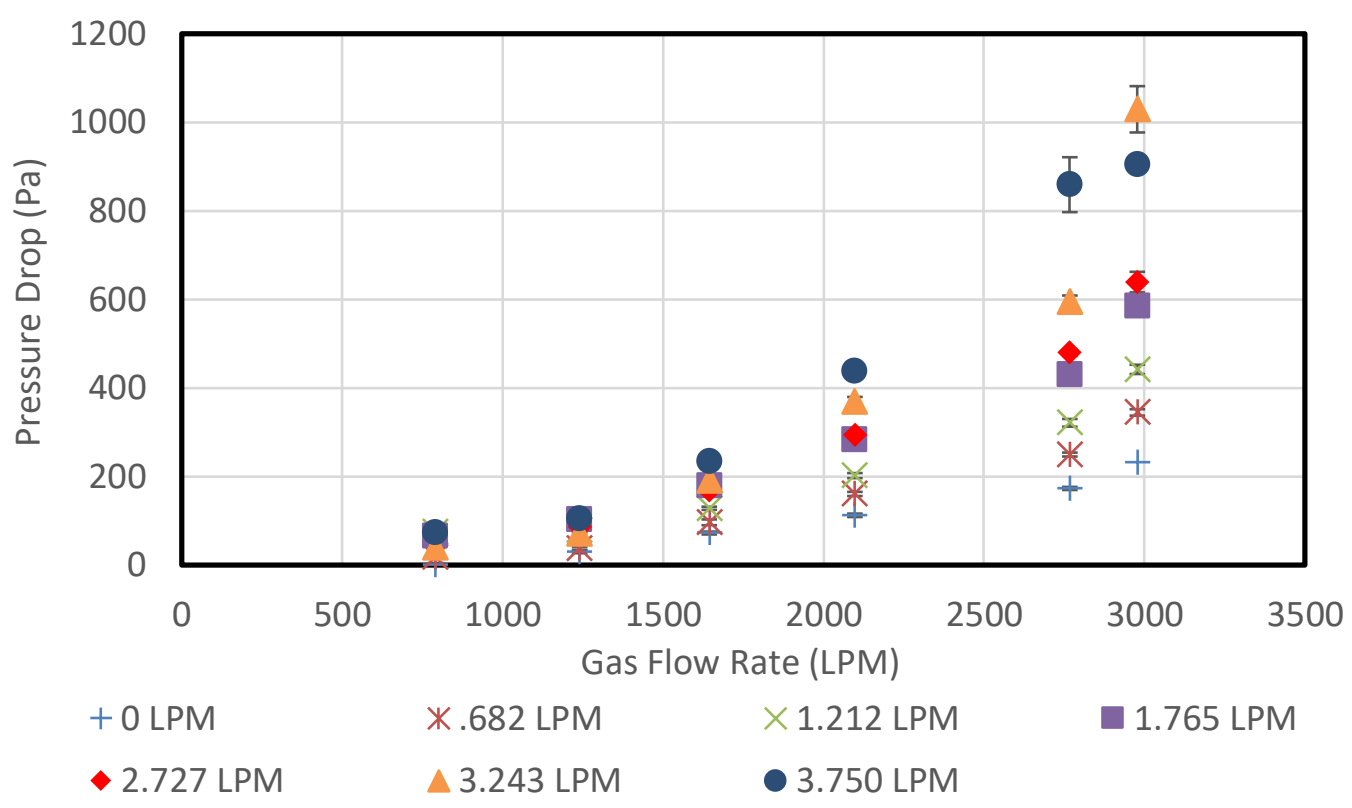

Figure 14. Pressure drop measurements for aluminum intensified device in an irrigated 8-inch column.

\subsubsection{Wettability of Packing Elements}

Next, a set of tests were performed to compare the wettability of the various packing elements. As described in section 3.1.4 Experimental Methods, each element was weighed, submerged into water, removed, and weighed again to determine the weight gain due to wetting by water after (1) mild shaking, (2) further shaking, (3) more shaking and drying of the external surface, (4) additional shaking and drying of the external surface. These sample treatments were consistent for all packing elements. Results from such measurements with the 3D printed polymer based devices shown in Figure 1 are presented in Figure 15, where it is demonstrated that wettability increases with packing density. The wettability of printed polymer and the printed aluminum intensified device was compared to that of the plastic and stainless steel Mellapak 250 baseline. Figure 16 shows that the printed aluminum intensified has a similar wettability to the Mellapak 250 stainless steel packing element. Both printed and commercial metal packing elements have much higher wettability than either the Sulzer plastic or polymer prints due to the hydrophilic nature of the metal devices. 


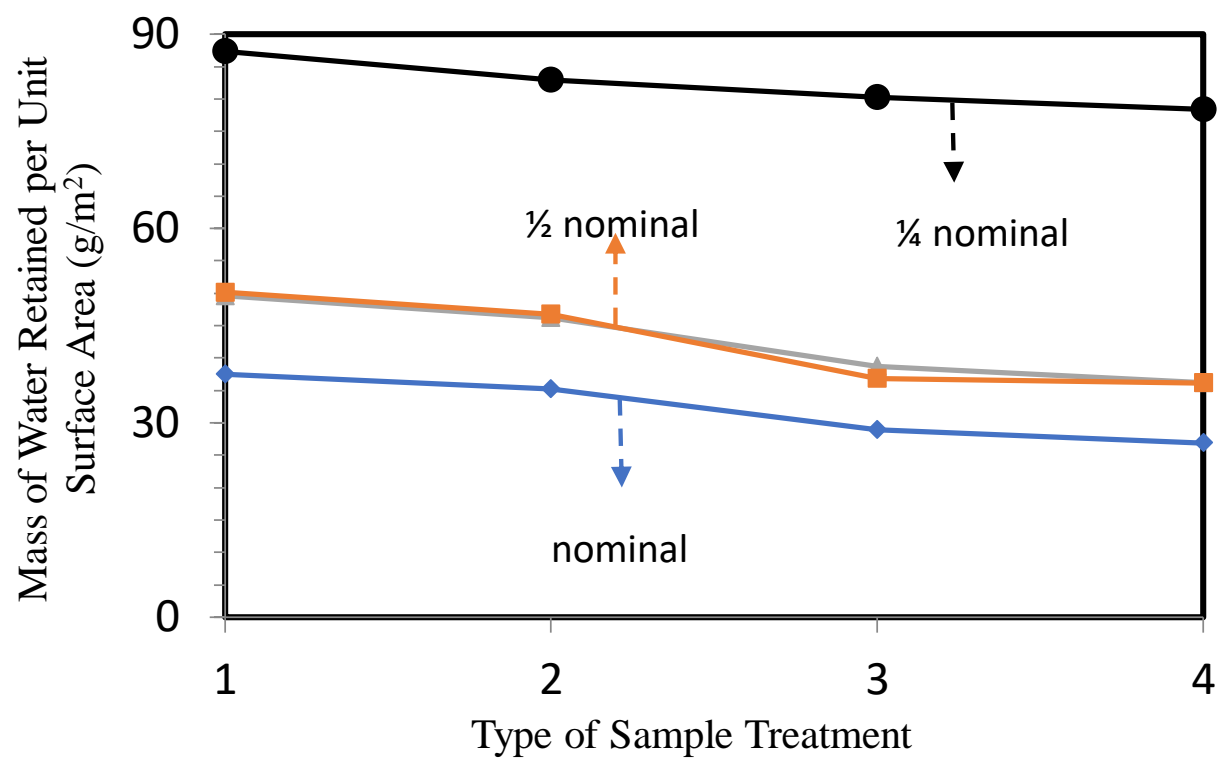

Figure 15 . Wettability measurements in terms of mass of water retained per unit surface area of packing elements for 3D printed polymer packing.

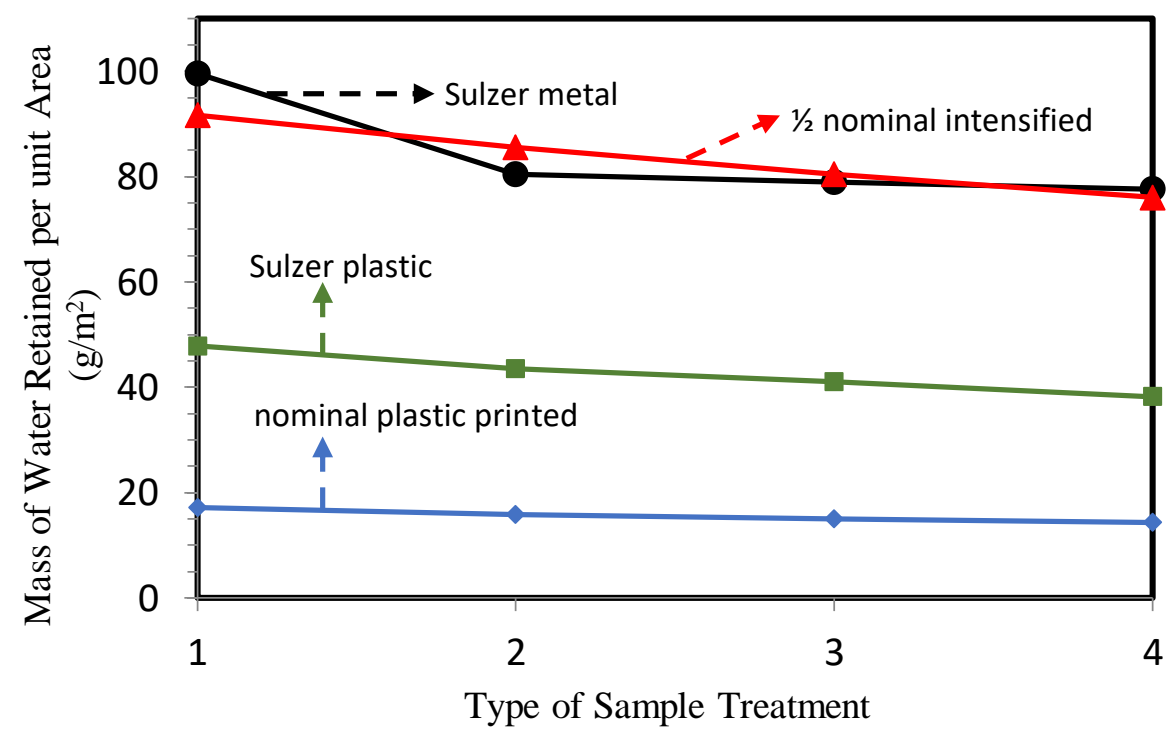

Figure 16. Wettability measurements in terms of mass of water retained per unit surface area of packing elements for commercial, polymer, and metal intensified packing.

\subsubsection{Discussion}

Pressure Drop for Dry System: As it is predicted, the dry-system pressure drop is shown to increase with packing density (pressure drop is proportional to packing density). The average errors between the predicted and experimental dry pressure drop values for the 8-inch column are: $13.35 \%$ for the nominal density, $9.33 \%$ for the $1 / 2$ nominal density, and $29.43 \%$ for the $1 / 4$ nominal 
density. For the 16-inch column, the 3D printed element is shown to have the largest pressure drop (as predicted). The average errors between these experimental and theoretical values are: $18.8 \%$ for the metal, $16.4 \%$ for the plastic, and $22.6 \%$ for the printed. A comparison between the printed polymer and printed aluminum intensified device shows that the intensified device exhibits a substantially higher pressure drop than the polymer, especially at higher gas flow rates.

Pressure Drop for Irrigated System: Pressure drop data for the irrigated column show some inconsistency with Mackowiak's model. For the theoretical values, there seem to be two distinct ranges showing pressure drop before the loading line is reached (gradual slope) and after loading (steeper slope). It appears that the model does not accurately predict where the loading line is and then predicts too drastic an increase in pressure drop after the loading line is reached. Pressure drop measurements on the aluminum intensified device likewise show two distinct regions. Comparisons with the pressure drop measurements on the 3D printed polymer show that pressure drop for aluminum is also substantially higher in an irrigated column.

Wettability: The wettability results for the 8 -inch column clearly show that, as packing density increases, more water is trapped on the surface of the polymer material. For the 16-inch column, the wettability of the metal element is approximately four times better than that of the 3D printed element. The wettability of the intensified aluminum device is similar to that of the stainless-steel packing element.

\section{DEVICE SCALE VALIDATION THROUGH DESIGN OF EXPERIMENTS}

\subsection{EXPERIMENTAL INFORMATION}

\subsubsection{Testing Facility}

Non-Reactive: A new testing facility designed to simulate thermal conditions in real absorbers was set up for thermal transport studies. The absorption column is composed of seven 8-inch Sulzer stainless steel commercial packing elements, with the intensified device installed near the center, and data sensors installed throughout, as shown in Figure 17. For the non-reactive studies, a fluid delivery system for air and water was installed. To adequately simulate the properties of flue gas, fluids were delivered to the column at controlled temperatures using a thermostatically controlled Tutco Farnam Heat Torch 150 inline air heater for gas, and a thermostatically controlled Eemax Lavadvantage tankless water heater for solvent. A schematic of the experimental system is illustrated in Figure 17.

For the purpose of testing heat transfer through the intensified device, air was delivered to the column from the bottom using a stainless-steel pipe in the shape of a $\mathrm{T}$, with the air coming out of the sides of the pipe, to prevent water (solvent) coming from the top of the column from entering the air line. Water was pumped to the top of the column where it entered a liquid distribution system composed of a tray, punctuated with small holes of 1/8-inch diameter for water flow, as shown in Figure 18, and two plastic pipes for air to escape. 

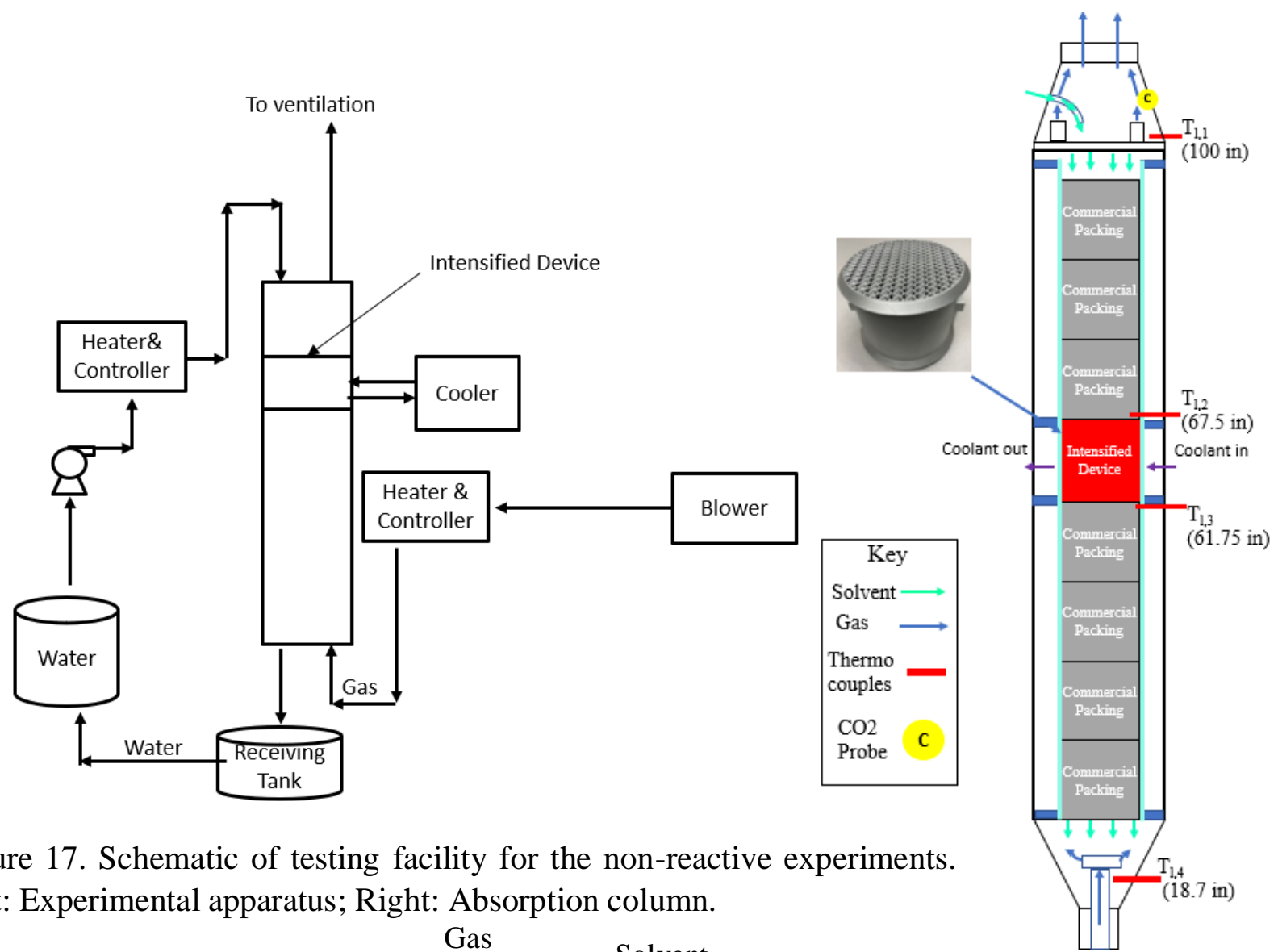

Figure 17. Schematic of testing facility for the non-reactive experiments. Left: Experimental apparatus; Right: Absorption column.

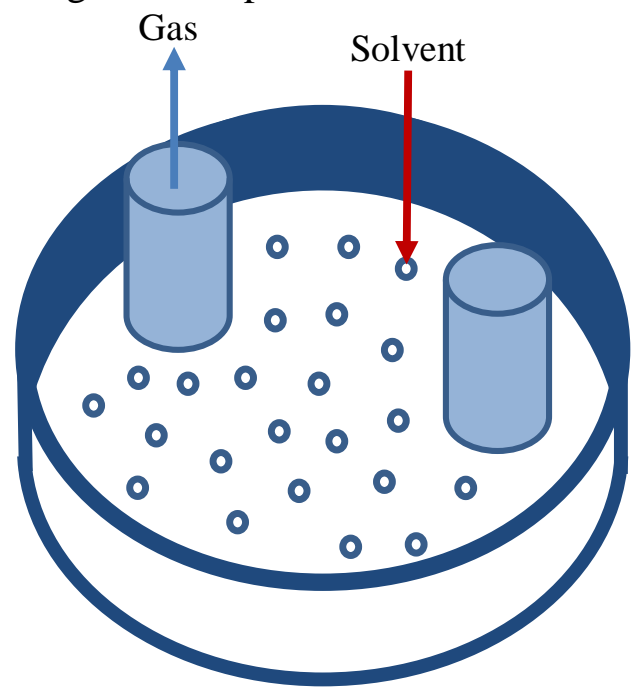

Figure 18. Liquid distribution system for absorption column.

Reactive Experiments: The testing facility was modified to accommodate the input of MEA and $\mathrm{CO}_{2}$, as shown in Figure 19. Two 50 gallon drums were added for storing the MEA solution, one serving as a supply tank and the other as return. The solvent was pumped out of the supply tank, and up to the top of the column by a peristaltic pump. After flowing down through the column, the solvent is collected at the bottom, where it is pumped into the return tank by a diaphragm pump. 
A drum heater was externally attached to the return tank after conducting experiments to regenerate the solvent. $\mathrm{CO}_{2}$ was supplied by pressurized gas cylinders that were connected to a mass flow controller. The $\mathrm{CO}_{2}$ mixes with the air stream at a tee before proceeding to the bottom of the column. An updated cooling system was used to supply coolant from a chilled tank.

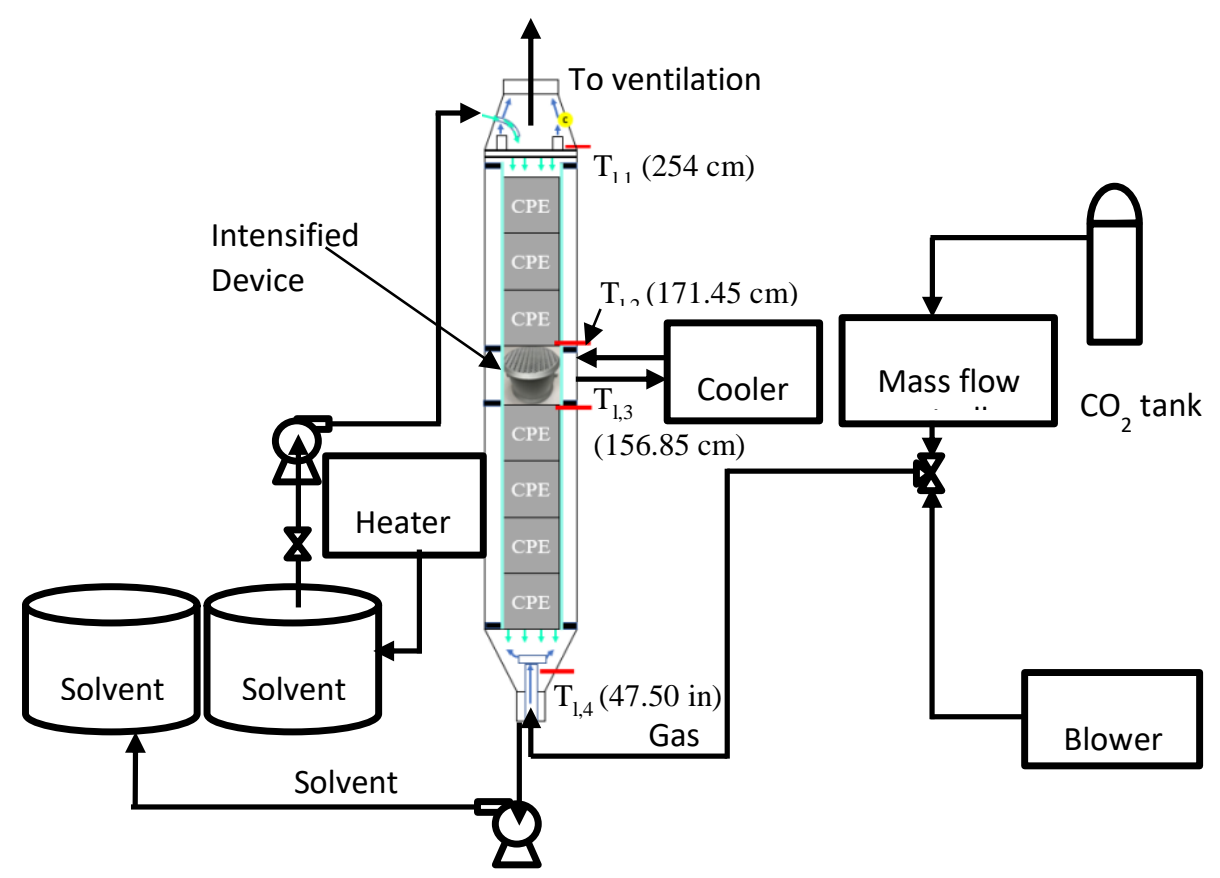

Figure 19. Schematic of testing facility and absorption column. CPE: Commercial Packing Element. C: $\mathrm{CO}_{2}$ measurement.

\subsubsection{Experimental Methods}

Non-reactive Heat Transfer: The non-reactive experiments were performed by heating the air and water before they entered the absorber. The flow rates and temperatures of the fluids were varied to study the effect of operating conditions on heat transfer rates. Six experiments in total were conducted, each with a different set of operating conditions. The temperature of the air was set to a constant of $80{ }^{\circ} \mathrm{C}$, although about $20{ }^{\circ} \mathrm{C}$ were lost between the heater and absorber entrance, while the water temperatures were $40{ }^{\circ} \mathrm{C}, 60{ }^{\circ} \mathrm{C}$, and $80{ }^{\circ} \mathrm{C}$. The air flow rates were $520 \mathrm{LPM}$ and 650 LPM, while the water flow rates were 1.36 LPM, 1.81 LPM and 2.26 LPM. The fluids were delivered to the column at the chosen temperatures until thermal steady state was achieved, at which point cooling was activated by pumping coolant through the intensified device. The temperatures of both fluids were continuously recorded at the locations shown in Figure 19, generating a time-dependent temperature plot. The average temperatures during steady state operation before and after cooling were calculated using the time-dependent plot and used to plot the temperature profile along the height of the column. The average temperatures were then used to approximate the heat transfer coefficient of the intensified device via the Log Mean Temperature Difference method. 
Reactive Heat and Mass Transfer: MEA solution and $\mathrm{CO}_{2}$ were introduced into the system to validate the beneficial effect of cooling. The temperature and flow rate of the solvent were held constant at $70{ }^{\circ} \mathrm{C}$ and 3.2 SLPM, respectively, and the MEA concentration was $~ 30 \%$. MEA was regenerated between experiments. Two series of experiments were conducted and, in both, the $\mathrm{CO}_{2}$ concentration was varied from 10 to $25 \%$; in the first set, it was varied by holding the $\mathrm{CO}_{2}$ flow rate constant at 90 SLPM and adjusting the air flow rate from 264 to 810 SLPM, while in the second set, the air flow rate was held constant at 360 SLPM and the $\mathrm{CO}_{2}$ flow rate was varied from 40 to 120 SLPM. This was done to investigate how $\mathrm{CO}_{2}$ and air flow would affect the efficacy of the cooling. Temperature data was acquired using the same software from the non-reactive experiments. Mass transfer measurements were obtained using a $\mathrm{CO}_{2}$ meter manufactured by $\mathrm{CO} 2$ Meter (Ormond Beach, FL). The exit concentration of $\mathrm{CO}_{2}$ was measured at the top of the column, the exit point for the gas stream. The nominal initial concentration was set by controlling the proportion of the flow rates using the mass flow controller and blower settings; however, it was verified by allowing the gas stream to continue flowing up the column after the solvent stream was cut off and recording the resulting concentration.

\subsection{MODELING}

\subsubsection{Heat and Mass Transfer Modeling}

The equations used to calculate the heat transfer coefficient and capture rate are described in detail in the Appendix.

\subsubsection{MFIX Simulations}

Heat transfer behavior in the non-reactive irrigated column studies was modeled using MFIX for validation purposes. MFIX is an open source multiphase flow modeling tool developed at the National Energy Technology Laboratory (NETL), and the MFIX -TFM (Two-Fluid Model) is an Eulerian-Eulerian model which supports a broad range of capabilities for dense, reacting, multiphase flows by representing the fluid and solids as interpenetrating continua. The MFIX model of solvent absorption, a custom extension of the MFIX-TFM model that models liquid and gas two phase flow has been used in the current effort for validation purposes. In this gas-liquid MFIX-TFM, the coupling of hydrodynamics and heat transfer for countercurrent gas-liquid flow through a packed column has been modeled. In applying this gas-liquid MFIX TFM, the model parameters have been carefully chosen so that the two-phase pressure drop, liquid holdup, wetting efficiency as a function of operating conditions are either matching with the experiment data or existing literature reports. The cooling from the coolant flow in the intensified device has been modeled as heat transfer with a fixed temperature coolant at a constant heat-transfer coefficient in the section where the intensified device is located. In addition, a uniform heat transfer coefficient along the column height has been applied to model the heat loss to the ambient air for this column with less than an ideal insulation.

\subsection{RESULTS}

\subsubsection{Non-Reactive Heat Transfer}


The temperature profile along the height of the column before and after cooling is shown for three sets of operating conditions in Figure 20. For these experiments, air temperature and flow rate were held constant at $80{ }^{\circ} \mathrm{C}$ and 650 LPM, respectively. The gas temperature closely followed the temperature of the liquid because of the intimate contact between them and because of air's low specific heat, so only the liquid temperatures are shown. This set of experiments shows only the effect of liquid flow rate which was varied from 1.81 LPM to 2.26 LPM. As expected, higher liquid flow rates correspond to higher temperatures across the board. The temperature profiles after cooling is activated demonstrate that, with appropriately sized cooling equipment, the intensified device can have a strong heat-exchange capability. The results, however, also reveal that the water is losing large amounts of heat even prior to the cooling, which limits the ability of the experiments to demonstrate the benefit of cooling. There are two likely culprits for this behavior. One is heat losses to ambient, and the other is vaporization of the liquid phase into the gas because of the low humidity air being pumped into the column, which would remove heat from the liquid and reduce the temperature of the system. Despite this limitation, these results demonstrate that the intensified device is a viable heat-exchange device in an irrigated column.

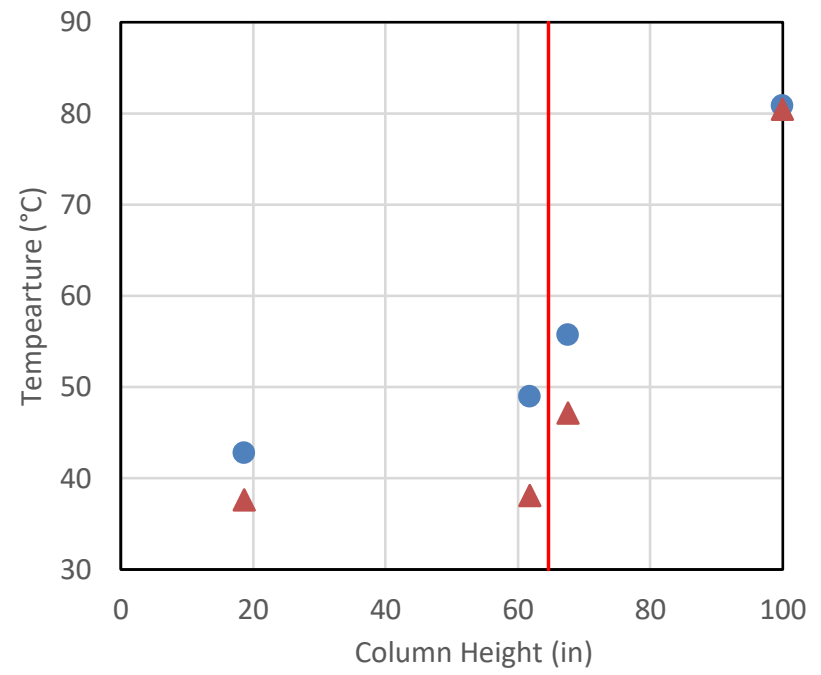

- Before Cooling $\Delta$ After Cooling Cooling Occurs

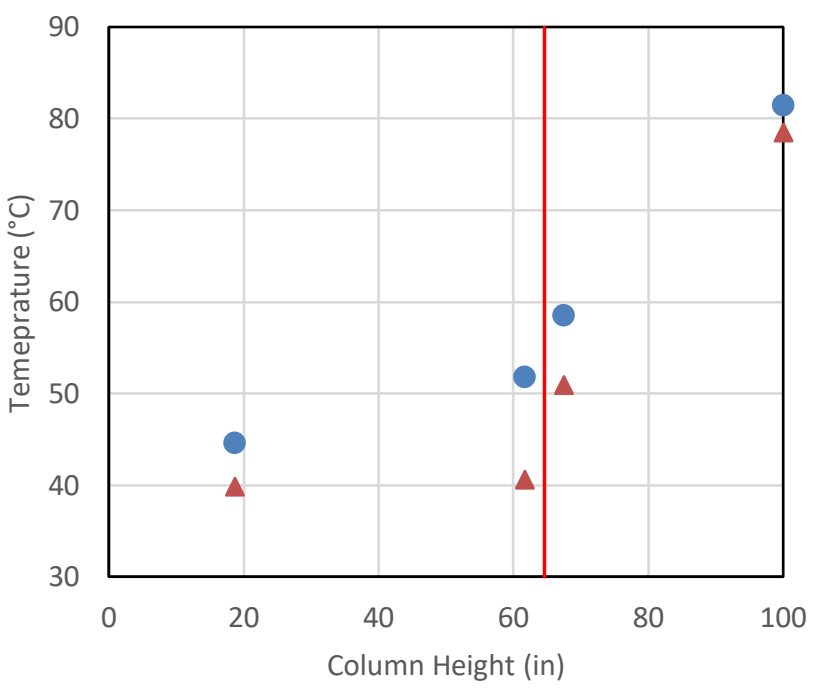

- Before Cooling

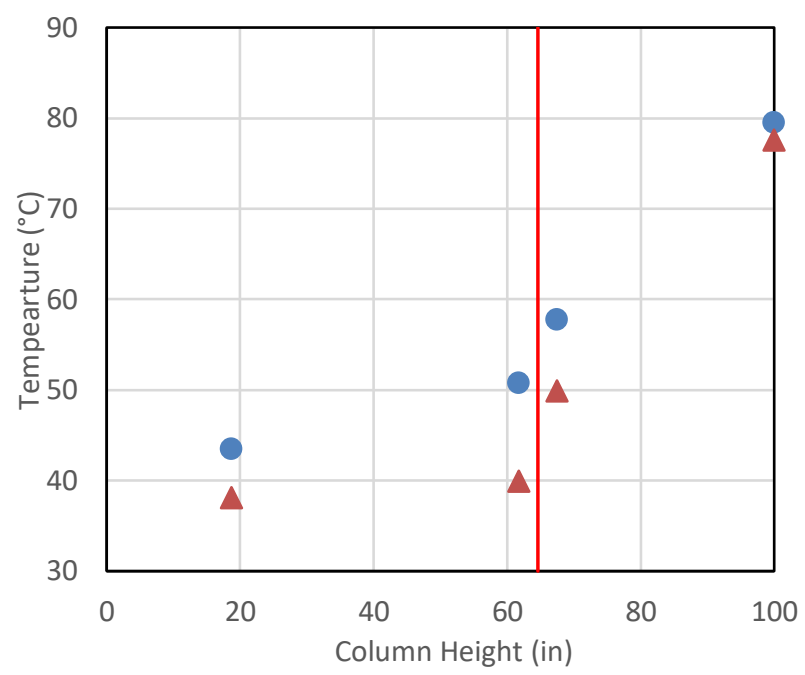

- Before Cooling $\Delta$ After Cooling Cooling Occurs

Figure 20. Liquid temperature profile along absorber height for non-reactive experiments. All variables were kept constant except the liquid flow rate.

(A) 1.36 LPM; (B) 1.81 LPM; (C) 2.26 LPM. 
The strength of the heat exchange capability was quantified by obtaining an approximation of the heat transfer coefficient of the intensified device using the Log Mean Temperature Difference method. The results are presented in Table 1 . The calculated values of the heat transfer coefficient exhibited little variance, as they ranged from 32-35 W/K-m².

Table 1. Calculated heat transfer coefficients for each experimental case

\begin{tabular}{|ccccc|}
$\begin{array}{c}\text { Air Flow } \\
\text { Rate (LPM) }\end{array}$ & $\begin{array}{c}\text { Air } \\
\text { Temperature } \\
\left({ }^{\circ} \mathbf{C}\right)\end{array}$ & $\begin{array}{c}\text { Water } \\
\text { Flow } \\
\text { Rate } \\
(\text { LPM) }\end{array}$ & $\begin{array}{c}\text { Water } \\
\text { Temperature } \\
\left({ }^{\circ} \mathbf{C}\right)\end{array}$ & $\begin{array}{c}\text { Heat Transfer } \\
\text { Coefficient } \\
(\mathbf{W} / \text { K-m2) }\end{array}$ \\
\hline $\mathbf{6 5 0}$ & 80 & 1.36 & 80 & 34.7 \\
$\mathbf{6 5 0}$ & 80 & 1.81 & 80 & 34.7 \\
$\mathbf{6 5 0}$ & 80 & 2.26 & 80 & 32.8 \\
$\mathbf{6 5 0}$ & 80 & 2.26 & 60 & 32.8 \\
$\mathbf{6 5 0}$ & 80 & 2.26 & 40 & 32.5 \\
$\mathbf{5 2 0}$ & 80 & 2.26 & 80 & 34.9 \\
\hline
\end{tabular}

The experimental heat-transfer results were compared to temperature profiles predicted by MFIX at the same temperature and flow conditions. The agreement between experimental and simulated temperature profiles of the uncooled irrigated column is remarkably close as the relative deviation from experimental results was between 0 and 14\%, with most experiments being well under 10\%. A comparison between experimental and simulation results for all data points is presented in a parity plot, shown in Figure 21. The accuracy of simulation predictions for the cooled is similarly satisfactory though to a lesser degree than the uncooled case. A comparison between experimental and simulated temperatures for the cooled system is presented in Figure 22. It is interesting to note that, compared to the uncooled cases, the simulation for the cooled system more frequently overpredicts the temperature. A possible contributing factor is that the simulation fails to predict that the liquid temperature above the intensified device is cooled down, not just the one below.

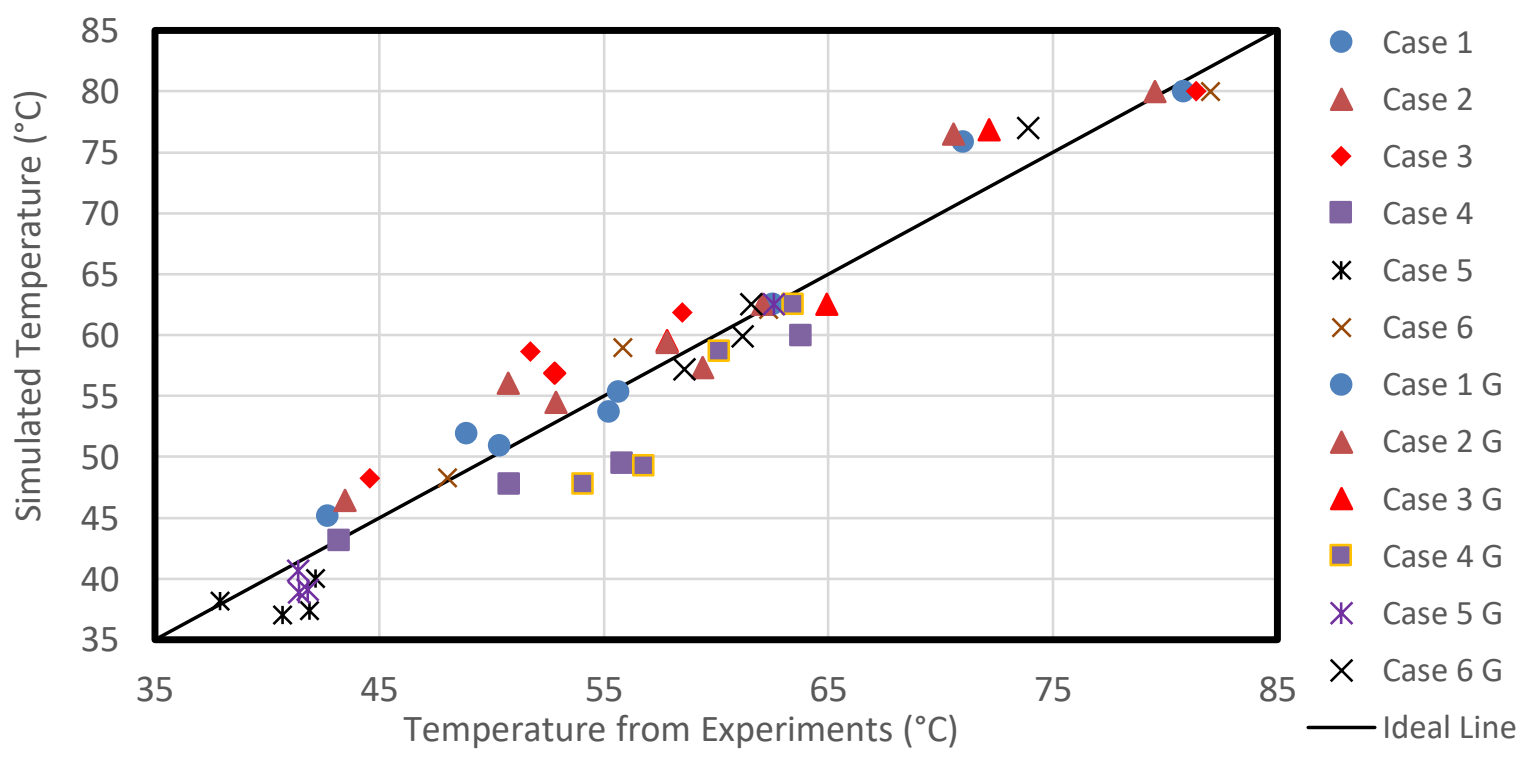

Figure 21. Parity plot for Uncooled Air- $\mathrm{H}_{2} \mathrm{O}$ system. Experimental vs simulated by the MFIX Model. 


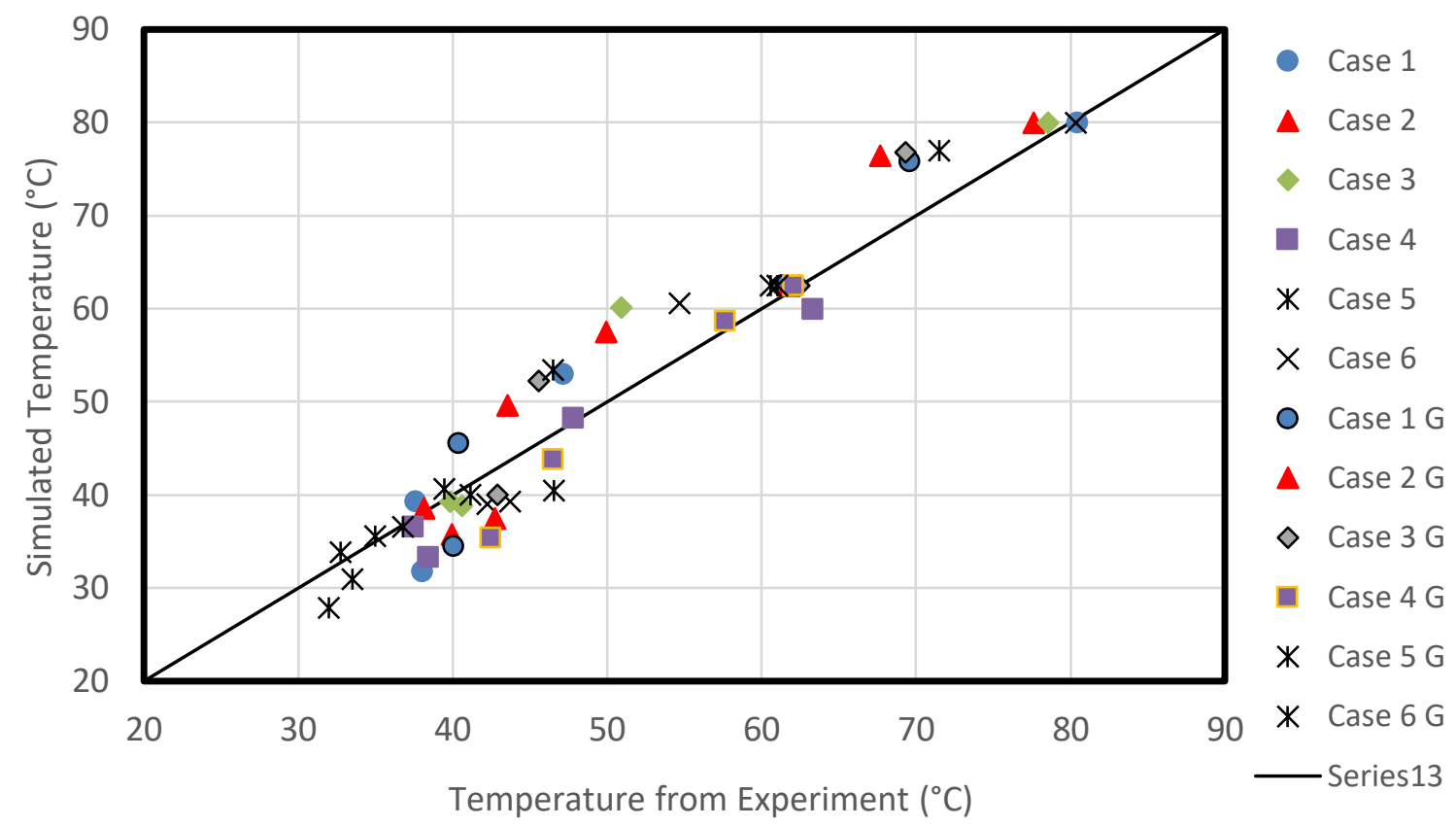

Figure 22. Parity plot for Cooled $\mathrm{Air}-\mathrm{H}_{2} \mathrm{O}$ system. Experimental vs simulated by the MFIX Model.

\subsubsection{Reactive System Mass Transfer}

Numerous experiments with a reactive $\mathrm{MEA}-\mathrm{CO}_{2}$ system were conducted. The first few experiments were conducted to calibrate the operating conditions for the experiments. Once suitable ranges of operating conditions were found, several experiments were conducted with the objective of investigating the effect of $\mathrm{CO}_{2}$ flow rate, air flow rate, and $\mathrm{CO}_{2}$ concentration on the carbon capture efficiency. A typical experiment is shown in Figure 23 with $\mathrm{CO}_{2}$ flow rate of 90 LPM and air flow rate of $360 \mathrm{LPM}$. The $\mathrm{CO}_{2}$ concentration and capture rate with respect to time are shown juxtaposed above the time-dependent temperature profile to demonstrate how changes in temperature correspond to a response in $\mathrm{CO}_{2}$ uptake. At these operating conditions, cooling supplied by the intensified device successfully enhanced the capture rate of $\mathrm{CO}_{2}$ by $11.5 \%$. These results demonstrate that cooling can enhance carbon capture given the appropriate operating conditions. The temperature profile along the column is also shown. Consistent with the literature, it was found that the location of the temperature bulge depends on the ratio of liquid to gas flow rates. In this case, the bulge was found to be just above the intensified device. We expected that enhancement to carbon capture would be greater if the temperature bulge was below or at the intensified device. 

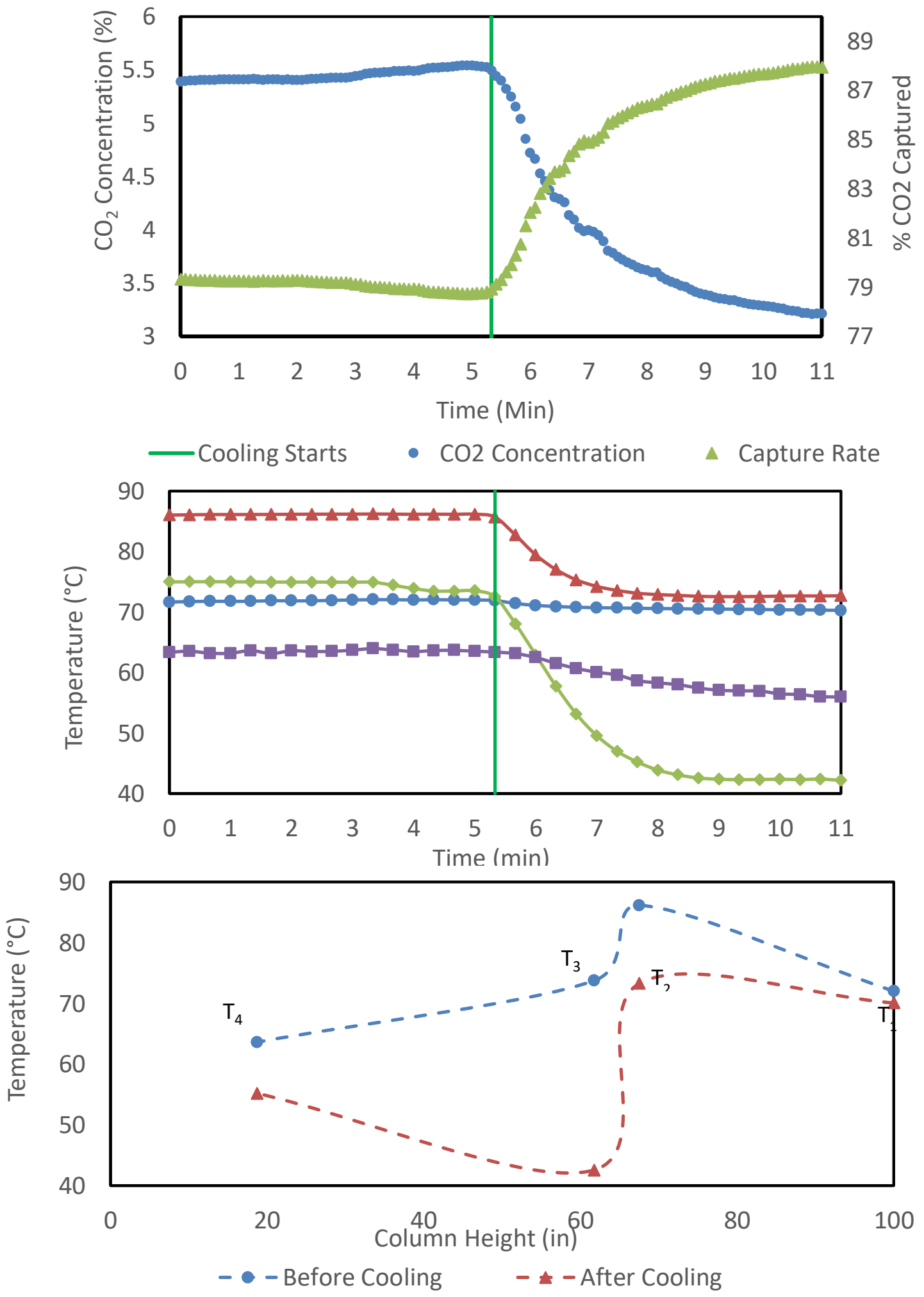

Figure 23. Top: Effect of cooling on $\mathrm{CO}_{2}$ concentration and molar $\mathrm{CO}_{2}$ capture rate at 360 LPM of air and 90 LPM of $\mathrm{CO}_{2}$. Middle: Time-dependent temperature profiles. Bottom: Steady-state liquid temperature profile before and after cooling. 
Two series of experiments were conducted for the reactive system: a constant air flow series and a constant $\mathrm{CO}_{2}$ flow series. The results of these series are presented in Table 2. These results show that, although all of the tested operating conditions improved the capture rate, the magnitude of the improvement depended significantly on the air flow rate, $\mathrm{CO}_{2}$ flow rate, and $\mathrm{CO}_{2}$ concentration. More specifically, there was a peak in capture rate enhancement in both series, at $20 \% \mathrm{CO}_{2}$ concentration for constant $\mathrm{CO}_{2}$ flow series and at $15 \%$ for the constant air flow series. The improvements to molar capture rate were $11.5 \%$ and $15.7 \%$, respectively.

Table 2. Improvements in capture efficiency for constant $\mathrm{CO}_{2}$ and constant air flow

\begin{tabular}{cc|ccccc|}
$\begin{array}{c}\text { Air } \\
\text { Flow } \\
\text { Rate } \\
(\mathrm{LPM})\end{array}$ & $\begin{array}{c}\mathrm{CO}_{2} \\
\text { Flow } \\
\text { Rate } \\
(\mathrm{LPM})\end{array}$ & $\begin{array}{c}\text { Moncentration } \\
(\%)\end{array}$ & $\begin{array}{c}\text { Molar } \\
\mathrm{CO}_{2} \\
\text { Cefure Rate } \\
\text { Cooling } \\
(\mathrm{mol} / \mathrm{min})\end{array}$ & $\begin{array}{c}\text { Molar } \\
\text { Capture } \\
\text { Rate After } \\
\text { Cooling } \\
(\mathrm{mol} / \mathrm{min})\end{array}$ & $\begin{array}{c}\text { Fractional } \\
\text { Increase } \\
(\%)\end{array}$ & $\begin{array}{c}\text { Capture } \\
\text { Efficiency }(\%) \\
\text { (Before Cooling } \\
\rightarrow \text { After } \\
\text { Cooling) }\end{array}$ \\
\hline 810 & 90 & 10 & 2.24 & 2.30 & 2.7 & $59.9 \rightarrow 61.2$ \\
510 & 90 & 15 & 2.75 & 2.90 & 5.5 & $73 \rightarrow 77$ \\
360 & 90 & 20 & 2.95 & 3.29 & 11.5 & $78 \rightarrow 88$ \\
264 & 90 & 25 & 3.52 & 3.57 & 4.3 & $94 \rightarrow 98$ \\
\hline 360 & 40 & 10 & 1.38 & 1.45 & 5.1 & $83 \rightarrow 87$ \\
360 & 63.5 & 15 & 1.53 & 1.77 & 15.7 & $58 \rightarrow 67$ \\
360 & 90 & 20 & 2.95 & 3.29 & 11.5 & $78 \rightarrow 88$ \\
360 & 120 & 25 & 3.07 & 3.28 & 6.9 & $62 \rightarrow 66$ \\
\hline
\end{tabular}

\subsubsection{Discussion}

The results from this study demonstrate that the intensified device cannot only be an effective heat exchanger that can substantially lower the temperature of an absorber, but its ability to cool the absorber does indeed boost the efficiency of chemical absorption. The magnitude of the improvement was shown to depend on air and $\mathrm{CO}_{2}$ flow rates. This occurs because of kinetic and thermodynamic effects. Increasing the air flow increases the resistance to mass transfer of $\mathrm{CO}_{2}$ from the gas stream into the liquid medium. Furthermore, when the $\mathrm{CO}_{2}$ concentration in the gas phase decreases, the equilibrium concentration of $\mathrm{CO}_{2}$ in the solvent is also expected to decrease. This behavior has an additional kinetic effect because it reduces the driving force for mass transfer. This explains why the capture efficiency was so low when the air flow was increased to 810 SLPM. At very low air flow rates, the resistance decreases and the driving force increases, which vastly improve the capture efficiency, hence the high capture rate of $94 \%$ that was achieved with an air flow rate of 264 SLPM before cooling. Because of the enhanced capture with decreased air flow, the reaction rate was very high, leaving less room for improvement. This explains the peak in the fractional increase in capture efficiency observed in the $\mathrm{CO}_{2}$ constant series. 


\section{CONCLUSION}

A 3D printed intensified packing device was successfully designed, printed, characterized, and tested for enhanced $\mathrm{CO}_{2}$ capture efficiency. Hydrodynamic testing demonstrated that 3D printed packing behaved similarly to commercially available packing on core metrics, such as pressure drop and wettability. The wettability of intensified aluminum packing is very similar to that of commercial stainless steel packing, which increases confidence that the printed intensified packing can have comparable hydrodynamic performance to commercial packing. Temperature measurements were made on an 8-inch column by attempting to cool down heated solvent. The heat transfer of the intensified device was subsequently calculated and found to be between 32 and $35 \mathrm{~W} / \mathrm{m}^{2} \mathrm{~K}$. Heat transfer testing demonstrated the device can successfully vent large amounts of excess heat in the absorber, despite limitations such as vaporization and heat loss to environment.

The intensified device proved capable of substantially enhancing $\mathrm{CO}_{2}$ capture by the amine solvent at appropriate operating conditions. The magnitude of the enhancement was found to be strongly dependent on air and $\mathrm{CO}_{2}$ flow rates. This success of the 3D printed intensified packing device represents an unprecedented achievement in the field of carbon capture research. This study has been a proof of concept for the application of a process intensification approach to carbon capture using additive manufacturing. There still remains ample opportunities for further optimization of key process parameters, such as device geometry and operating conditions. Future work can focus on further refining and optimizing those parameters. 


\section{APPENDIX A. Heat and Mass Transfer Modeling}

\section{A.1 Mass Transfer Calculations}

The capture efficiency of the absorber was calculated by performing a mass balance over the absorption column for the gas stream. The amount of air that enters the column can be assumed to be the same amount that exits because the column is sealed from the environment and the air does not appreciably participate in the reaction. Air contains oxygen which does react with MEA; however, that reaction occurs very slowly and only uses up trace amounts of reactants, so oxidative degradation of MEA can safely be neglected for this experiment. Also, the $\mathrm{CO}_{2}$ content of the air is much smaller than the $\mathrm{CO}_{2}$ added for the experiment, and can be neglected as well. The material balance for the air entering (1) and leaving the column (2) is:

$$
Q_{1} C_{a i r, 1}=Q_{2} C_{a i r, 2}
$$

where $Q$ is flow rate of the gas stream and $C$ is percent concentration. The concentration of the air was not directly measured, so the equation is stated in terms of the $\mathrm{CO}_{2}$ concentration:

$$
Q_{1}\left(1-C_{\mathrm{CO}_{2}, 1}\right)=Q_{2}\left(1-C_{\mathrm{CO}_{2}, 2}\right)
$$

Assuming there are no leaks to the environment, the $\mathrm{CO}_{2}$ that enters the absorber must be equal to the $\mathrm{CO}_{2}$ that exits, plus the $\mathrm{CO}_{2}$ that is absorbed in the reaction. The resulting $\mathrm{CO}_{2}$ balance is shown in Equation 6, where $\zeta$ is the $\mathrm{CO}_{2}$ absorbed rate by the solvent.

$$
Q_{1} C_{C O 2,1}=Q_{2} C_{C O 2,2}+\zeta
$$

Substituting equation 2 into equation 3 and solving for $\zeta$ yields:

$$
\zeta=Q_{1} C_{C O 2,1}-\frac{Q_{1}\left(1-C_{C O_{2}, 1}\right) C_{C O 2,2}}{\left(1-C_{\mathrm{CO}_{2}, 2}\right)}
$$

Once the rate of $\mathrm{CO}_{2}$ captured by the solvent is known, the capture efficiency can be obtained by dividing the $\mathrm{CO}_{2}$ capture rate by the $\mathrm{CO}_{2}$ flow rate entering the absorber:

$$
\% \text { Capture Rate }=\frac{\zeta}{Q_{1} C_{C O 2,1}} \times 100
$$

\section{A.2 Heat Transfer Calculations}

An approximation of the heat transfer coefficient of the intensified device was obtained by employing the Log Mean Temperature Difference Method. First, the heat transfer rate of a fluid can be calculated by:

$$
q=\dot{m} c_{p} \Delta T
$$


where $q$ is the heat transfer rate, $c_{p}$ is the specific heat of the fluid, and $\Delta T$ is its change in temperature. When the heat transfer occurs between two phases, the overall heat transfer coefficient, $U$, can be calculated using equation 7 , where $A$ is the contact surface area and $\Delta T_{l m}$ is the log mean temperature difference.

$$
U=\frac{q}{A \Delta T_{l m}}
$$

The log mean temperature difference is a logarithmic temperature average of the temperature difference between hot and cold fluids and can be calculated using equation 8 where $\Delta T_{1}$ and $\Delta T_{2}$ are differential temperatures depending on flow pattern:

$$
\Delta T_{l m}=\frac{\Delta T_{2}-\Delta T_{1}}{\ln \left(\frac{\Delta T_{2}}{\Delta T_{1}}\right)}
$$

The differential temperatures are calculated using Equations 9 and 10:

$$
\begin{aligned}
\Delta T_{2} & =T_{h, i}-T_{c, i} \\
\Delta T_{1} & =T_{h, o}-T_{c, o}
\end{aligned}
$$




\section{APPENDIX B. Estimate of the Contributions of Vaporization and Wall Losses to Heat Transfer in Irrigated Absorption Column}

Due to the large magnitude of the heat losses from water vaporization and through the walls seen in the uncooled temperature profile, an attempt was made to approximate the magnitude of these contributions. The combined effect of both contributions can be obtained by performing an energy balance over the entire column using the measured temperatures at the entrance and exit. In Case 3 , water entered the column at $81{ }^{\circ} \mathrm{C}$, and exited at $44{ }^{\circ} \mathrm{C}$. The heat lost by the water in the column is therefore $5.8 \mathrm{~kW}$. The air entered the column at $65{ }^{\circ} \mathrm{C}$ and exited at $72^{\circ} \mathrm{C}$, gaining $100 \mathrm{~W}$. Subtracting the heat gained by the air from the heat lost by the water results in $5.7 \mathrm{~kW}$ of heat lost. This calculation yields the combined losses from heat loss through walls and vaporization.

To provide a more detailed breakdown, we can estimate the size of the vaporization component by assuming that the air being drawn into the blower is at $50 \%$ relative humidity and the air exiting the column is at saturation. We assume the latter because the blower draws in air from the room and, during the experiments, the room's heavy-duty ventilation system, which draws air from outdoors into the room, is active. We assume $50 \%$ because that was the measured relative humidity during the day that an experiment was conducted.

Based on these assumptions, we calculated the amount of energy it would require to evaporate enough water to increase the relative humidity of an airstream flowing at $650 \mathrm{~L} / \mathrm{min}$ from $50 \%$ at $25^{\circ} \mathrm{C}$, roughly the temperature outside, to $100 \%$ at $72^{\circ} \mathrm{C}$, the measured temperature at the exit. The calculations showed that, based on these assumptions, $0.117 \mathrm{~kg} / \mathrm{min}$ of water would need to be evaporated, which would require approximately $4.65 \mathrm{~kW}$ of energy. Based on these calculations, we estimate the heat loss due to vaporization to be $4.6 \mathrm{~kW}$ and the heat loss through the walls to be $1.1 \mathrm{~kW}$ for these operating conditions. Similar estimates were performed for the remaining experimental cases, which are shown in Table 4.

Table 3. Experimental Cases in Unreactive Irrigated Absorption Column Experiments

\begin{tabular}{|ccccc|}
\hline Case & $\begin{array}{c}\text { Air Flow Rate } \\
\text { (LPM) }\end{array}$ & $\begin{array}{c}\text { Air Temperature } \\
\left({ }^{\circ} \mathbf{C}\right)\end{array}$ & $\begin{array}{c}\text { Water Flow Rate } \\
\text { (LPM) }\end{array}$ & $\begin{array}{c}\text { Water Temperature } \\
\left({ }^{\circ} \mathbf{C} \text { ) }\right.\end{array}$ \\
\hline $\mathbf{1}$ & 650 & 80 & 1.36 & 80 \\
$\mathbf{2}$ & 650 & 80 & 1.81 & 80 \\
$\mathbf{3}$ & 650 & 80 & 2.26 & 80 \\
$\mathbf{4}$ & 650 & 80 & 2.26 & 60 \\
$\mathbf{5}$ & 650 & 80 & 2.26 & 40 \\
$\mathbf{6}$ & 520 & 80 & 2.26 & 80 \\
\hline
\end{tabular}


Table 4. Heat losses due to vaporization and through the walls

\begin{tabular}{|l|cccccc|}
\hline & Case 1 & Case 2 & Case 3 & Case 4 & Case 5 & Case 6 \\
\hline Total Heat loss (W) & 3500 & 4439 & 5704 & 3284 & 963 & 5223 \\
Vaporization Heat Loss (W) & 3464 & 4370 & 4605 & 2917 & 906 & 4528 \\
Wall Heat Loss (W) & 36 & 69 & 1099 & 367 & 57 & 695 \\
\hline
\end{tabular}




